INTERNATIONAL FOOD POLICY

RESEARCH INSTITUTE

sustainable solutions for ending hunger and poverty

IFPR ${ }^{\circledR}$ A member of the CGIAR consortium

IFPRI Discussion Paper 01268

April 2013

\title{
Group Lending with Heterogeneous Types
}

\section{Li Gan}

Manuel A. Hernandez

\section{Yanyan Liu}

Markets, Trade and Institutions Division 


\section{INTERNATIONAL FOOD POLICY RESEARCH INSTITUTE}

The International Food Policy Research Institute (IFPRI) was established in 1975 to identify and analyze national and international strategies and policies for meeting the food needs of the developing world on a sustainable basis, with particular emphasis on low-income countries and on the poorer groups in those countries. IFPRI is a member of the CGIAR Consortium.

\section{PARTNERS AND CONTRIBUTORS}

IFPRI gratefully acknowledges the generous unrestricted funding from Australia, Canada, China, Denmark, Finland, France, Germany, India, Ireland, Italy, Japan, the Netherlands, Norway, the Philippines, South Africa, Sweden, Switzerland, the United Kingdom, the United States, and the World Bank.

\section{AUTHORS}

Li Gan, Texas A\&M University

Professor, Economics

gan@econ.tamu.edu

Manuel A. Hernandez, International Food Policy Research Institute

Research Fellow, Markets, Trade and Institutions Division

Yanyan Liu, International Food Policy Research Institute

Research Fellow, Markets, Trade and Institutions Division

Notices

1. IFPRI Discussion Papers contain preliminary material and research results. They have been peer reviewed, but have not been subject to a formal external review via IFPRI's Publications Review Committee. They are circulated in order to stimulate discussion and critical comment; any opinions expressed are those of the author(s) and do not necessarily reflect the policies or opinions of IFPRI.

2. The boundaries and names shown and the designations used on the map(s) herein do not imply official endorsement or acceptance by the International Food Policy Research Institute (IFPRI) or its partners and contributors.

Copyright 2013 International Food Policy Research Institute. All rights reserved. Sections of this material may be reproduced for personal and not-for-profit use without the express written permission of but with acknowledgment to IFPRI. To reproduce the material contained herein for profit or commercial use requires express written permission. To obtain permission, contact the Communications Division at ifpri-copyright@cgiar.org. 


\section{Contents}

Abstract $\quad$ V

Acknowledgments $\quad$ vi

1. Introduction 1

2. A Simple Model of Group Lending with Peer Selection and Moral Hazard 3

3. Data 5

4. Empirical Model 9

5. Results 12

6. Concluding Remarks 23

Appendix A: Supplementary Tables and Figures 24

Appendix B: Solution to the Model with Peer Selection and Moral Hazard 30

References $\quad 34$ 


\section{Tables}

3.1-Summary statistics $\quad 6$

3.2 -Intragroup default behavior $\quad 8$

5.1-Probability of default, two-type model 13

5.2-Conditional marginal effects (percentage points) 16

5.3-Unconditional marginal effects (percentage points) 17

5.4-Predictive performance of alternative models 20

A.1-Data description $\quad 24$

A.2-Sorting based on observables $\quad 25$

A.3-Probability of default, one-type model 25

\section{Figures}

5.1-Comparison of Type I errors $\quad 21$

5.2-Comparison of Type II errors $\quad 22$

A.1-Histogram of percentage of loan repaid by member 27

A.2-Location of villages in Andhra Pradesh and group default behavior 27

A.3-Distribution of intragroup default behavior by different group characteristics 29 


\begin{abstract}
Group lending has been widely adopted in the past thirty years by many microfinance institutions as a means to mitigate information asymmetries when delivering credit to the poor. This paper proposes an empirical method to address the potential omitted-variable problem resulting from unobserved group types when modeling the repayment behavior of group members. We estimate the model using a rich dataset from a group-lending program in India. The estimation results support our model specification and show the advantages of relying on a type-varying method when analyzing the probability of default of group members. In particular, our model helps to better understand the factors driving repayment behavior, which may differ across group types, and shows a higher predictive power than standard singleagent choice models.
\end{abstract}

Keywords: group lending, heterogeneous types, repayment behavior 


\section{ACKNOWLEDGMENTS}

We thank Alan de Brauw, Arun Chandrasekhar, Carlos Martins-Filho, Eduardo Nakasone, Annabel Vanroose, Ruth Vargas-Hill and seminar participants at the Pacific Development Conference, Winter Meetings of the Econometric Society and IFPRI for their helpful comments. We gratefully acknowledge financial support from the CGIAR Research Program on Policies, Institutions and Markets. We also thank the staff of the Center for Economics and Social Studies, particularly Prof. S. Galab, for their support and collaboration in making the data available. Finally, we thank Zhe Guo for his valuable research assistance. 


\section{INTRODUCTION}

Since the establishment of Grameen Bank in Bangladesh in the mid-1970s, microfinance has boomed. As of December 2010, 3,652 microfinance institutions reported reaching more than 205 million clients worldwide, and every two out of three borrowers were among the poorest when they took their first loan (Maes and Reed 2012). Such expansion can be partly attributed to the widely adopted practice of group lending in microfinance programs. In contrast to individual lending, group lending with joint liability grants a loan to a group of borrowers, and the whole group is liable for the debt of any individual member in the group. ${ }^{1}$ This practice allows microfinance programs to rely mainly on information advantages among group members, rather than on their financial collateral, to mitigate information asymmetries between lenders and potential borrowers. Given that the poor often lack appropriate financial collateral, group-lending programs provide a feasible way of extending credit to poor people, who are usually kept out of traditional banking systems.

Second In most group-lending programs, individuals voluntarily form a group based on a set of common characteristics, which usually are observed by peers but not by lenders (and econometricians). This peer selection in the group formation process helps lessen adverse selection, as individuals screen each other when forming groups. On this matter, Ghatak $(1999,2000)$ and van Tassel (1999) showed that in a context of individuals with heterogeneous risk types and asymmetric information (that is, where borrowers know each other's type but lenders do not), group lending with joint liability will lead to the formation of relatively homogenous groups of either safe or risky borrowers. ${ }^{2}$ The intuition behind the model is that although a borrower of any type prefers a safe partner because of lower expected jointliability payments, safe borrowers value safe partners more than risky partners because they repay more often. This positive assortative matching is supported by empirical evidence in Ahlin (2009), who also found that borrowers will antidiversify risk within groups in order to lower their chances of facing liability for group members.

However, in a similar manner as self-selection, peer selection creates an omitted-variable problem in the empirical literature on repayment behavior (Karlan 2007). The omitted variables may include, for example, the risk type, entrepreneurial spirit, economic opportunities, solidarity, reciprocity, and trust among group members, all of which affect repayment performance and are likely to be correlated, with the indicators generally used to account for group heterogeneity and social ties when modeling repayment behavior. Yet, different from the omitted-variable problem due to self-selection, the omitted-variable problem due to peer selection has largely been overlooked in the literature (Hermes and Lensink 2007). Most of the empirical studies that explore determinants of repayment in group-lending programs treat the group as a decision maker and employ single-agent choice models to examine how different group characteristics, including proxies for social ties, affect the group repayment performance (see, for example, Sharma and Zeller 1997; Zeller 1998; Wydick 1999; Paxton, Graham, and Thraen 2000; Hermes, Lensink, and Mehrteab 2005; Ahlin and Townsend 2007; Cull, Demirguc-Kunt, and Morduch 2007).

In addition, groups may differ in their effort levels and effectiveness of peer monitoring and peer pressure among members, which are also unobserved by lenders and have direct implications on the observed repayment performance of group members. In addition to mitigating adverse selection through peer screening, group lending helps alleviate moral hazard behavior and enforce repayment, because members can more closely monitor each other's use of loans and exert pressure to prevent deliberate

\footnotetext{
${ }^{1}$ Joint liability is one of the most common varieties of group loan contracts.

${ }^{2}$ In contrast, Armendariz de Aghion and Gollier (2000) suggested that non assortative matching equilibrium can exist when a borrower knows her own type but has no ex ante information about the other borrowers' types. Guttman (2008) indicated that negative assortative matching is possible if a riskier borrower can provide side payments to get a safer peer. However, side payments are usually infeasible when the group is relatively large. In addition, group members often know each other well enough, because groups are typically formed by people living in the same geographical area or in contiguous areas. In fact, the information advantage (local information) of group members over lenders is a main factor in justifying the idea of group lending over individual lending. See also Ghatak and Guinnane (1999).
} 
default. ${ }^{3}$ The success of peer monitoring and peer pressure efforts across groups may be further correlated with peer screening, because individuals are more likely to select safe borrowers who are also less costly to monitor and less likely to deliberately default. Overall, group-level unobservables may result from a combination of factors, including endogenous group formation due to ex ante peer selection and ex post peer monitoring and pressure effects.

This paper proposes and applies an empirical method to address the potential omitted-variable problem in group lending resulting from unobserved types. We use a mixture model to explicitly account for unobserved group types when modeling the repayment behavior of group members. In the model, individuals make repayment decisions based on their unobserved group type, as well as on observable individual and loan characteristics. Average member characteristics and other group and village characteristics help, in turn, to identify the group types. We further allow the marginal effects in the repayment equation to vary across types. We estimate the model using a rich dataset from a group-lending program in Andhra Pradesh in India. ${ }^{4}$ Although the type-varying groups in the empirical model may be explained by peer selection and variations (if any) in peer efforts and the effectiveness of peer monitoring and enforcement rules, as well as by other unobserved factors like social cohesion, disentangling these effects is beyond the scope of the study. ${ }^{5}$

The study also intends to contribute to the ongoing debate of whether group-lending programs are sustainable and able to achieve and maintain sound repayment performance, while serving poor borrowers, without the support of third parties such as international organizations. Armendariz de Aghion and Morduch (2005) showed, for example, that from 1985 to 1996, Grameen Bank experienced losses close to 18 percent of their outstanding loans, after properly adjusting for their portfolio size. It is also often argued that the high transaction costs faced by microfinance institutions in identifying and screening their clients, processing applications, and collecting repayments keep interest rates high and prevent these organizations from reaching new clients and expanding their operations (Armendariz de Aghion and Morduch 2004; Shankar 2006; Field and Pande 2008). Understanding the factors affecting repayment performance, which may vary by (unobserved) group types, is thus of great policy relevance. In particular, more accurate risk-scoring tools can help overcome information asymmetries by aiding lending institutions in better classifying their potential clients and understanding the factors driving their behavior, further promoting the development and sustainability of microcredit markets.

The estimation results support our model specification and show the advantages of relying on this method when analyzing the probability of default of group members. The model clearly distinguishes two group types: groups in which members are more inclined to fulfill their credit obligations and groups in which members are more inclined to default. We also find important differences in the marginal effects of the different individual and loan characteristics included in the repayment equation, which suggests that the underlying factors driving repayment behavior may differ across group types. In addition, the typevarying model shows a higher predictive performance than standard probabilistic models, which can help further attenuate information asymmetries in microlending.

The remainder of the paper is organized as follows: Section 2 further discusses the implications of group lending with joint liability and heterogeneous types, using a simple model of adverse selection and moral hazard. Section 3 describes in detail the group-lending program considered for the study and the data. Section 4 presents the empirical model used to account for the potential omitted-variable problem resulting from unobserved group types when modeling the repayment behavior of group members. Section 5 reports and discusses the estimation results. Section 6 concludes.

\footnotetext{
${ }^{3}$ See, for example, Stiglitz (1990), Varian (1990), Banerjee, Besley, and Guinnane (1994), Armendariz de Aghion (1999), and Chowdury (2005) for theoretical models showing how group lending with joint liability may help solve moral hazard and monitoring problems.

${ }^{4}$ Group loans account for 93 percent of microfinance in India (Shankar 2006).

${ }^{5}$ For a formal evaluation of ex post peer effects on individual repayment behavior, refer to Karlan (2007) and Li, Liu, and Deininger (2012). Karlan (2007) exploited a unique quasi-random group-formation process to isolate peer selection and examined the impact of monitoring and enforcement on repayment. Li, Liu, and Deininger (2012) estimated a structural model that takes into account interactions across group members and incorporates group-level unobservables as random effects.
} 


\section{A SIMPLE MODEL OF GROUP LENDING WITH PEER SELECTION AND MORAL HAZARD}

Ghatak (1999, 2000) and van Tassel (1999) developed models that describe how joint liability with heterogeneous types and local information can lead to positive assortative matching through peer selection. We extend Ghatak's (1999) base model by taking into account both peer selection and moral hazard. We allow individuals to differ on their risk type (creditworthiness) and on their level of effort.

Assume that borrowers are risk neutral and endowed with one risky project, which requires one unit of capital. Individuals have no initial wealth and must borrow the required amount of capital. Further assume that there are two types of borrowers: risky individuals of type $a$ and safe individuals of type $b{ }^{6}$ The probability of success of borrower $i$ 's project $\left(k_{i}\right)$ depends on her inherent probability of success ( $\left.p_{i}>0\right)$, which is determined by her risk type, and on her effort level $\left(e_{i} \geq 0\right)$, where $i=a, b$. In particular, a risky borrower has a success probability of $k_{a}=p_{a}+e_{a}$, whereas a safe borrower has a success rate of $k_{b}=p_{b}+e_{b}$, with $p_{a}<p_{b}$ and $0<k_{a}, k_{b} \leq 1$. Without loss of generality, if the project is successful, the output takes the value of $Y$; otherwise, it is 0 .

In the presence of local information, all borrowers know one another's risk type, but the outside lender (bank) does not. Following Ghatak (1999), in the absence of financial collateral, the bank requires potential borrowers to form groups of size two, where both members are jointly liable for each other. The bank offers to each group the joint-liability contract $(r, q)$, where $r>0$ is the gross interest rate and $q>0$ is the liability payment. Hence, $r$ is the payment made by the individual who succeeds, and $q$ is the additional payment made by the individual when she succeeds and her partner fails. A borrower who fails pays the bank nothing. The expected payoff for type $i$ borrower matched with type $j$ borrower is, then, given by

$$
E \pi_{i j}=\left(p_{i}+e_{i}\right) Y-\left(p_{i}+e_{i}\right) r-q\left(p_{i}+e_{i}\right)\left(1-p_{j}-e_{j}\right)-1 / 2 \gamma e_{i}^{2},
$$

where the disutility of the effort is captured by $-1 / 2 \gamma e_{i}^{2}$, with parameter $\gamma>0$.

We assume a noncooperative game setting in which each borrower maximizes her own expected payoff $E \pi_{i j}$ with respect to her effort $e_{i}$. We solve the maximization problem in Appendix B. The main results are summarized below:

1. A borrower's optimal effort level $\left(e_{i j}^{*}, i=a, b\right)$ is higher if she is a safe type and/or if her partner is a safe type. That is, $e_{b b}^{*}>e_{a b}^{*}>e_{b a}^{*}>e_{a a}^{*}$.

2. A borrower prefers a safe partner to a risky partner, regardless of her own type. That is, $E \pi_{b b}^{*}>E \pi_{b a}^{*}$ and $E \pi_{a b}^{*}>E \pi_{a a}^{*}$.

3. Joint liability with varying risk types and effort levels leads to a single equilibrium of positive assortative matching in group formation. More specifically, $E \pi_{b b}^{*}-E \pi_{b a}^{*}>E \pi_{a b}^{*}-E \pi_{a a}^{*}$. A safe borrower's net expected loss of having a risky partner compared with having a safe partner is higher than the next expected gain of a risky borrower having a safe partner compared with having a risky partner. As noted by Ghatak (1999), this equilibrium condition

\footnotetext{
${ }^{6}$ In this model, we assume that the type refers to the riskiness of borrowers. However, the type could also refer to other factors associated with the creditworthiness of borrowers, such as their entrepreneurial spirit, reciprocity, solidarity, trust, or level of responsibility. In the empirical setup, the group types may aggregate all of these factors.
} 
is similar to the optimal sorting property in Becker (1993), in that borrowers not in the same group should not be able to form a group without making one or both of them worse off.

The second and third results above are consistent with the results from Ghatak (1999). The intuition is that although a borrower of any type prefers a safe partner because of lower expected jointliability payments, safe borrowers value safe partners more than they do risky borrowers because safe partners repay more often their loans and are more likely to realize the gains of having a safe partner. By allowing the probability of success to also depend on the effort level of borrowers, we additionally find that groups of safe partners exhibit a higher effort, which translates into further higher repayment probabilities. This result reinforces the notion of a separating equilibrium, in that borrowers of the same type will pair together, and safe pairs will show a further higher likelihood of repayment than will risky pairs.

We also allow for a cooperative game setting in which each borrower maximizes the total payoff of her group with respect to her effort. We obtain the same key results of the noncooperative game: a single equilibrium with positive assortative matching in which groups of safe partners exhibit a higher effort than do groups of risky partners. The derivation under this alternative setup is detailed in Appendix B.

Thus, a simple framework with peer selection and moral hazard helps to show how joint liability can lead to a separating equilibrium with the coexistence of two opposed groups: a group of safe borrowers with a higher probability of repayment (success) reinforced by a higher level of effort to succeed, and a group of risky borrowers with a lower probability of repayment and lower efforts to succeed. The coexistence of different group types, driven by unobserved factors such as risk and effort levels, implies the necessity to account for potential group types when modeling repayment behavior in group lending. Certainly, there are mechanisms other than joint liability through which group lending without financial collateral can lead to higher or lower repayment rates and varying group types - take, for example, the unobserved informal risk sharing and social cohesion among group members. ${ }^{7}$ The proposed empirical method that follows is flexible enough to allow for varying group types driven by a wide set of factors that are not necessarily observable and that may shape a group's repayment behavior.

\footnotetext{
${ }^{7}$ For empirical evidence on this matter, see Gine and Karlan (2009) and Feigenberg, Field, and Pande (2011).
} 


\section{DATA}

\section{Background and Data}

The groups under study are located in Andhra Pradesh in India. ${ }^{8}$ They are organized following a new selfhelp groups (SHG) model promoted by the World Bank that targets poor women in rural areas. The model combines savings generation and microlending with social mobilization. In particular, women who generally live in the same village or habitat voluntarily form SHGs with the understanding of a jointliability mechanism. A typical SHG consists of 10-20 members who meet regularly to discuss social issues and activities. During group meetings, each member also deposits a small thrift payment into a joint bank account. Once enough savings have been accumulated, group members can apply for internal loans that draw from the accumulated savings at an interest rate to be determined by the group. After the group establishes a record of internal savings and repayment, it becomes eligible for loans through a commercial bank or program funds. This process of internal savings and repayments helps members further screen one another, as some individuals may leave the group before obtaining a formal loan.

The group as a whole then borrows from a commercial bank or program funds, and all group members are held jointly liable for each other's debts. The group generally allocates the loan to its members on an equal basis, and the group is not eligible for further loans unless it has made full repayment. ${ }^{9}$ The loans may be used for labor activities or consumption smoothing. Groups also have the option of implementing nonlending programs with the support of the program funds, such as in-kind credit for subsidized rice, marketing, and insurance programs.

In this study, we focus on the first "expired" loan borrowed from commercial banks by each group. An expired loan is a loan that had passed its due date by the time the survey was conducted. In Andhra Pradesh, commercial banks carry out microfinance activities in non-overlapped territories, so that groups located in contiguous villages borrowed from the same bank.

The sample includes 1,110 different group loans that were allocated to 12,833 women. The data are from an SHG survey conducted between August and October 2006 in eight districts in Andhra Pradesh. These districts were chosen to represent the state's three macro regions (Rayalaseema, Telangana, and Coastal Andhra). ${ }^{10}$ The SHG survey contains socioeconomic characteristics of group members (households), such as education background, housing condition, land and livestock ownership, occupation, and caste. It also includes group characteristics, such as age, meeting frequency of members, and programs and services available within the group. More important, the survey includes information on all loans taken between June 2003 and June 2006 as recorded from SHG account books. This information includes the terms of each loan, the members to whom the loan was allocated, and how much of the loan had been repaid by each member at the time of the survey. ${ }^{11}$

The SHG survey was complemented with a previous village survey that covered all the villages from which the SHGs were sampled. From the village survey, we construct four indicators to account for the economic environment of the sample groups. These indicators include availability of financial institution, public bus, telephone, and post office.

Table 3.1 presents descriptive statistics of our full sample. ${ }^{12}$ Panel 1 reports member characteristics based on 12,833 observations, whereas Panel 2 reports group and loan characteristics based on 1,110 observations. Approximately 23 percent of the group members are literate, and 31 percent belong to a scheduled tribe or scheduled caste. Around 6 percent of the members are disabled or have

\footnotetext{
${ }^{8}$ Andhra Pradesh is the fourth largest state in India by area and the fifth largest by population.

${ }^{9}$ Naturally, a woman who maintains a good record and who leaves a group in which not all members fulfill their loan obligations may join another group in the future.

${ }^{10}$ The eight districts are Srikakulam, Adilabad, Anantapur, Kadapa, Warangal, Nalgonda, Nellore, and Visakhapatnam

${ }^{11}$ The survey instrument included a separate section in which the allocation of loans to members (member loans) was recorded. See Li, Liu, and Deininger (2012) for further details on how the information on group loans and member loans was matched.

${ }^{12}$ A detailed description of the variables used in the analysis is provided in Table A.1 in the Appendix.
} 
family members who are disabled. About 65 percent of households own some land; 33 percent live in pucca houses, 22 percent in kutcha houses, and the other 45 percent in semi-pucca houses. ${ }^{13}$ Similarly, about 61 percent are agricultural laborers who do not own land or who own such a small amount of land that they have to provide agricultural labor for others; 20 percent are self-employed agricultural workers; and the rest have other occupations, such as those self-employed or employed in nonagricultural sectors and housewives. Table 3.1 also indicates that 80 percent of the group members in our sample fully repaid their loan by its due date (that is, they did not default). Figure A.1 in the Appendix plots a histogram of the percentage of the loan repaid by each member. It follows that most of the data points are clustered at the endpoints, which supports the discrete treatment of the repayment (default) behavior in the empirical model.

Table 3.1-Summary statistics

\begin{tabular}{lcccc}
\hline \multicolumn{1}{c}{ Variable } & Mean & Std. Dev. & Min. & Max. \\
\hline Panel 1: Individual characteristics & $\mathbf{1 2 , 8 8 3}$ observations) & & & \\
If defaulted & 0.20 & 0.40 & 0.00 & 1.00 \\
If literate & 0.23 & 0.42 & 0.00 & 1.00 \\
If disabled member in household & 0.06 & 0.24 & 0.00 & 1.00 \\
If owns land & 0.65 & 0.48 & 0.00 & 1.00 \\
If lives in pucca house & 0.33 & 0.47 & 0.00 & 1.00 \\
If lives in kutcha house & 0.22 & 0.42 & 0.00 & 1.00 \\
If self-employed agricultural worker & 0.20 & 0.40 & 0.00 & 1.00 \\
If agricultural laborer & 0.61 & 0.49 & 0.00 & 1.00 \\
If belongs to scheduled tribe or caste & 0.31 & 0.46 & 0.00 & 1.00 \\
If belongs to leading caste & 0.92 & 0.27 & 0.00 & 1.00 \\
Panel 2: Group and loan characteristics $\mathbf{( 1 , 1 1 0}$ groups) & & & \\
Average member characteristics & & & & 0.94 \\
\% literate & 0.22 & 0.21 & 0.00 & 0.94 \\
\% disabled member in household & 0.05 & 0.10 & 0.00 & 0.95 \\
\% own land & 0.59 & 0.31 & 0.00 & 0.95 \\
\% live in pucca house & 0.32 & 0.31 & 0.00 & 0.95 \\
\% live in kutcha house & 0.21 & 0.26 & 0.00 & 0.95 \\
\% self-employed agricultural worker & 0.18 & 0.30 & 0.00 & 0.95 \\
\% agricultural laborer & 0.56 & 0.36 & 0.00 & 1.00 \\
\% belong to scheduled tribe or caste & 0.31 & 0.43 & 0.00 & 1.00 \\
\% belong to leading caste & 0.91 & 0.14 & 0.36 & 1.00 \\
Other group and village characteristics & & & & 1.00 \\
Age of group (years) & 6.44 & 2.49 & 1.00 & 1.00 \\
If group has food credit program & 0.28 & 0.45 & 0.00 & 0.00 \\
If group has marketing program & 0.15 & 0.35 & 0.00 \\
If group has insurance program & 0.25 & 0.43 & 0.00 & \\
If group meets at least monthly & 0.89 & 0.31 & 0.00 & 0.00 \\
If located in Telangana & 0.45 & 0.50 & 0.00 & \\
If located in Rayalaseema & 0.26 & 0.44 & & \\
\hline
\end{tabular}

${ }^{13}$ A pucca house has walls and roofs made of burnt bricks, stones, cement concrete, and timber, whereas a kutcha house uses less-sophisticated materials, such as hay, bamboo, mud, and grass. A semi-pucca house uses a combination of materials from the other two types. 
Table 3.1-Continued

\begin{tabular}{lcccc}
\hline \multicolumn{1}{c}{ Variable } & Mean & Std. Dev. & Min. & Max. \\
\hline If located in Coastal Andhra & 0.29 & 0.45 & 0.00 & 1.00 \\
Number of group members & 12.52 & 2.37 & 7.00 & 20.00 \\
If financial institution in village & 0.34 & 0.47 & 0.00 & 1.00 \\
If public bus in village & 0.66 & 0.48 & 0.00 & 1.00 \\
If telephone in village & 0.75 & 0.43 & 0.00 & 1.00 \\
If post office in village & 0.63 & 0.48 & 0.00 & 1.00 \\
Loan characteristics & & & & \\
Amount of loan (rupees) & 3,338 & 2,685 & 400 & 25,000 \\
Number of members with loan & 11.61 & 3.24 & 2.00 & 20.00 \\
Annual interest rate (\%) & 12.83 & 3.10 & 6.00 & 25.00 \\
Length of loan (years) & 1.11 & 0.46 & 0.17 & 5.00 \\
If repayment at least monthly & 0.96 & 0.19 & 0.00 & 1.00 \\
If loan due in 2004 & 0.11 & 0.31 & 0.00 & 1.00 \\
If loan due in 2005 & 0.49 & 0.50 & 0.00 & 1.00 \\
If loan due in 2006 & 0.40 & 0.49 & 0.00 & 1.00 \\
\hline
\end{tabular}

Source: Authors' own calculations.

Turning to the group and loan characteristics, the groups range from 7 to 20 members and have close to 13 members on average. The groups are from all of the three macroregions in the state: about 45 percent are located in Telangana, 26 percent in Rayalaseema, and the remaining 29 percent in Coastal Andhra. The average group age is six years, and in roughly 9 of every 10 groups, the members meet on a regular basis (at least monthly). About 28 percent of the groups have a food credit program (in-kind credit for subsidized rice), 15 percent have a marketing program, and 25 percent have an insurance program. The group loan was allocated on average to 12 members, and the average loan size received by a member is 3,338 rupees (about US\$67). The annual rate of interest is about 12.8 percent, which is much lower than the prevailing rate of moneylenders in India. The average duration of a loan is roughly one year, and the majority of loans ( 96 percent) required the groups to make repayments at least monthly.

\section{Preliminary Analysis}

A first look at the data is indicative of a separating equilibrium with apparently two group types. Table 3.2 shows that in more than 9 out of every 10 groups in our sample, either all of the members did not default or all of them did default. In particular, in 76 percent of the groups (848 out of 1,110 groups), all group members fully repaid their loans or never defaulted; in another 17 percent of the groups (188 groups), all group members defaulted. As discussed earlier, this repayment behavior may result from a combination of elements: The observed repayment pattern may reflect positive assortative matching ("matching likes") in group formation, predicted by our basic model in which borrowers of the same type group together in equilibrium in a context of joint liability, heterogeneous types, and asymmetric information between borrowers and lenders. ${ }^{14}$ Recall that under the SHG model, groups have an initial period of internal savings and repayment, which also serves as an extended (ex ante) screening period, prior to applying for a commercial loan. This initial period also promotes social interaction among members, which may result in stronger social ties among them (see also Feigenberg, Field, and Pande 2011). The observed pattern may also reflect variations (if any) in the level of effort and effectiveness of peer monitoring and peer pressure across groups, which may be correlated with peer screening. The

\footnotetext{
${ }^{14}$ For a formal test on homogenous risk matching in group lending, see Ahlin (2009).
} 
model developed above indicates that groups composed of safe borrowers will also exhibit a higher level of effort than groups composed of risky borrowers. Hence, a preliminary look at the data suggests the existence of mainly two group types: a "responsible" group of apparent low-risk individuals with probably high efforts and/or effective monitoring and enforcement rules and strong social cohesion, and an "irresponsible" group of apparent high-risk individuals with probably low efforts and/or ineffective monitoring and enforcement rules and a lack of social cohesion. ${ }^{15}$

Table 3.2-Intragroup default behavior

\begin{tabular}{lrc}
\hline Default Behavior & \multicolumn{2}{c}{ Groups } \\
\cline { 2 - 3 } & $\#$ & $\%$ \\
\hline If none of the members defaulted & 848 & 76.4 \\
If all of the members defaulted & 188 & 16.9 \\
If some of the members defaulted & 74 & 6.7 \\
& & \\
Total & 1,110 & 100.0 \\
\hline
\end{tabular}

Source: Authors' own calculations.

There is also the possibility of external factors, such as a negative weather shock, affecting the likelihood of repayment of all members in a group, who generally live close to one another and perform similar labor activities. However, in our sample, groups in which all members defaulted are not always concentrated at a particular location, which reduces the possibility of specific weather shocks or other contextual factors explaining intergroup variation on default behavior. In particular, Figure A.2 shows that villages with a high proportion of groups in which all members default are well dispersed across the eight districts of our sample in Andhra Pradesh. ${ }^{16}$ In addition, the estimation results presented below indicate that the variables included in the repayment equation (individual and loan characteristics) have a differentiated effect on the likelihood of default by group type, which further supports the existence of type-varying groups.

To further examine the possibility of homogenous sorting among groups, Table A.2 reports the number of groups in which the intragroup variance is less than or equal to the overall variance, considering all groups in the same village or mandal for different borrower characteristics. ${ }^{17}$ (A mandal is equivalent to a subdistrict in India and comprises several villages.) The characteristics include literacy, household characteristics, land ownership, occupation, and caste. The results show that individuals with similar observable characteristics appear to group together. On average, in almost 70 percent (72 percent) of the cases, the intragroup variance for a given characteristic is smaller than the intravillage (intramandal) variance. There is a relatively higher degree of homogeneity among group members in terms of belonging to a scheduled tribe or caste and of being a self-employed agricultural worker and a lower level of homogeneity in terms of literacy.

Overall, a preliminary look at the data indicates the coexistence of different types of groups in our sample. This suggests the necessity to allow for potential unobserved group types when examining repayment behavior in group lending.

\footnotetext{
${ }^{15}$ The existence of the mixed group (7 percent of our group sample) suggests that the observed defaults are not necessarily strategic defaults. If some members fail to repay some installments, the other members still have the incentive to repay on time, because they do so in hope that delinquent members will repay their installments on a future date. In addition, individuals who maintain a good repayment record are more likely to join a "better" group in the future (if necessary). Formally addressing the dynamic aspects of installment repayments is beyond the scope of our paper.

${ }^{16}$ For areas with available weather data (rainfall) and vegetation information (Normalized Difference Vegetation Index) during the period of analysis, we did not find any significant correlation between these measures and default behavior.

${ }^{17}$ The comparisons exclude all villages (150 out of 457) and mandals ( 3 out of 97) in which there is only one group in the village or mandal.
} 


\section{EMPIRICAL MODEL}

This section develops an empirical model to address the potential omitted-variable problem in group lending with unobserved types. We use a mixture model to explicitly account for unobserved group types when evaluating the repayment behavior of individual members. The unobserved types may result from peer selection, as well as from variations in the level of effort and effectiveness of peer monitoring and pressure and other unobserved factors like social cohesion. The probability of default is conditional on the unobserved type and depends on observable individual and loan characteristics, whereas average member characteristics and other group and village characteristics (observed by lenders) may help identify the group type to which the individual belongs.

Let the default behavior of individual $i$ in group $j$ be given by

$$
D_{i j}=1\left(\alpha+X_{i j} \beta_{1}+C_{j} \beta_{2}+T_{j}^{*}+u_{i j}>0\right)
$$

where $D_{i j}$ is the observed binary outcome - that is, $D_{i j}$ equals 1 if the individual defaults (if the individual does not fully repay her loan); otherwise, it equals $0 ; \alpha$ is a constant; $X_{i j}$ is a vector of observable individual characteristics; $C_{j}$ is a vector of loan characteristics; $T_{j}^{*}$ is the unobserved group type, which is likely correlated with $X_{i j}$ (and $C_{j}$ ); and $u_{i j}$ is an error term. On the correlation between $X_{i j}$ and $T_{j}^{*}$, we can think, for example, of a proxy for the social ties of an individual included in $X_{i j}$ and potentially correlated with the social ties of her peers (who generally live in the same neighborhood), which partly describes $T_{j}^{*}$.

If group heterogeneity is solely based on observables, the observed group characteristics $\left(Z_{j}\right)$, such as average member characteristics, and other group controls, including social ties, would be sufficient to identify the group types, and $Z_{j}$ could be used as a proxy for $T_{j}^{*}$ to estimate equation (2) using a standard probabilistic regression (for example, probit, logit). However, the unobserved group type is more accurately characterized by both observable and unobservable factors such that $T_{j}^{*}=Z_{j} \delta+W_{j}+\varepsilon_{j}$, where $W_{j}$ is unobserved, $Z_{j}$ and $W_{j}$ are potentially correlated, and $\varepsilon_{j}$ is an error term. Following the previous example, a proxy for a group's social ties or connections, included in $Z_{j}$, is likely correlated with the unobserved economic opportunities and entrepreneurial spirits of the group members, which are comprised in $W_{j}$ and further affect repayment.

Hence, a standard probabilistic regression of equation (2) with only $Z_{j}$ on the right side will result in an omitted variable bias, as $W_{j}$ will be embedded in the error term. Another option is to incorporate the unobserved group component or type as fixed effects in a conditional logit model. Yet a fixed-effects logistic regression mainly exploits within-group variation and will drop all groups without intragroup differences in default behavior (that is, more than 90 percent of our sample). Furthermore, the observed factors affecting repayment performance may vary by group type.

To address this potential omitted-variable problem, we propose an alternative model in which group heterogeneity can be captured by allowing groups to be one of two types with a specific probability. In particular, we assume that $T_{j}^{*}$ can take two possible values - that is, $T_{j}^{H}$ if the group is responsible, and $T_{j}^{L}$ if the group is irresponsible. In broader terms, we can think of the first group as being mainly composed of "safe" borrowers with effective monitoring and enforcement efforts and high 
reciprocity and solidarity among members and the second group as a group of "risky" borrowers with less effective monitoring and enforcement efforts and low reciprocity and solidarity among members. We could easily relax this assumption to allow for a wider set of types (based on different combination of factors), but our data seem to support a two-type model. In particular, we also estimated a three-type model, but the two-type model provides a better fit based on the Schwarz Bayesian information criterion (SBIC). ${ }^{18}$

The repayment behavior of individual $i$ in group $j$ is given by

$$
D_{i j}=\left\{\begin{array}{cc}
1\left(\alpha_{H}+X_{i j} \beta_{1, H}+C_{j} \beta_{2, H}+u_{i j, H}>0\right) & \text { if } T_{j}^{*}=T_{j}^{H} \\
1\left(\alpha_{L}+X_{i j} \beta_{1, L}+C_{j} \beta_{2, L}+u_{i j, L}>0\right) & \text { if } T_{j}^{*}=T_{j}^{L}
\end{array} .\right.
$$

In this specification, the effect of $T_{j}^{*}$ is absorbed by the constant terms $\alpha_{H}$ and $\alpha_{L}$, and

$\operatorname{Cov}\left(X_{i j}, u_{i j}\right)=0$. We further allow for varying coefficients across group type, which permits us to capture varying effects of different factors on repayment behavior by type. ${ }^{19}$

The probability of being in type- $H$ group $\left(T_{j}^{*}=T_{j}^{H}\right)$ can be further modeled as

$$
\operatorname{Pr}\left(T_{j}^{*}=T_{j}^{H}\right)=\operatorname{Pr}\left(\bar{X}_{j} \delta_{1}+G_{j} \delta_{2}+v_{j}>0\right)
$$

where $\bar{X}_{j}$ is a vector of average characteristics of group members, $G_{j}$ is a vector of group and village controls $\left(G_{j}\right)$, and $v_{j}$ is an error term. ${ }^{20}$ Hence, although the individual characteristics of each group member $\left({ }^{X_{i j}}\right)$ help us approximate their default probability, the average characteristics of all group members $\left(\bar{X}_{j}\right)$ can help us identify their group type. The member characteristics considered for the analysis include literacy, land ownership, housing condition, occupation, and caste. ${ }^{21}$ Thus, although belonging to a certain caste, for example, may directly affect the likelihood of repayment, the percentage of members belonging to a similar caste (included in $\bar{X}_{j}$ ) can serve as a proxy for social ties within the group, which will also have an indirect effect in the probability of default. ${ }^{22}$ We also account for loan characteristics $\left(C_{j}\right)$ in the repayment equation (for example, loan amount, interest rate, length, repayment frequency), and we use other group and village controls ( $\left.G_{j}\right)$ to help us identify the group type (for example, age, number of members, location, access to programs and services).

Note that since $T_{j}^{*}$ is likely determined by both observable $\left(\bar{X}_{j}, G_{j}\right)$ and unobservable $\left(W_{j}\right)$ characteristics, the parameters in equation (4) may not be consistently estimated. However, even though

\footnotetext{
${ }^{18}$ The SBIC of the two-type model is 0.838 versus 0.849 of the three-type model. Furthermore, the predicted probability of being in the potential third type group is close to 0 .

19 This flexibility is similar to Gan and Hernandez (2013), who allowed for varying coefficients across potential collusive and noncollusive regimes when modeling the pricing and occupancy rate behavior of hotels under a switching regression framework.

${ }^{20}$ The underlying assumption is that the probability of being a certain group type varies with some observable characteristics - in this case, with $\bar{X}_{j}$ and $G_{j}$.

${ }^{21}$ This type of personal information is also generally disclosed during credit application processes.

${ }^{22}$ In particular, we generate a variable of percentage members belonging to the leading caste (defined as the caste with the largest number of members in the group) to capture social ties. Unfortunately, we do not have more detailed information, such as number of relatives, to more accurately control for social ties within the group.
} 
we do not observe $W_{j}$, it does not result in inconsistent estimates of the parameters in the repayment equation (3); we only require some (but not full) information about $T_{j}^{*}$ to identify the parameters in the repayment equation. Intuitively, the identification is similar to that underlying a two-stage least squares (2SLS) procedure, where the consistency of the 2SLS estimations does not require the consistency of the first-stage regression (see also Gan, Huang, and Mayer 2011).

The key identifying assumption in the proposed model is that conditional on the group type, both observable and unobservable factors that characterize $T_{j}^{*}$ are not related to the probability of defaulting. In particular,

$$
\operatorname{Pr}\left(D_{i j}=1 \mid T_{j}^{*}=T_{j}^{H}, \bar{X}_{j}, G_{j}, W_{j}\right)=\operatorname{Pr}\left(D_{i j}=1 \mid T_{j}^{*}=T_{j}^{H}\right) .
$$

Consequently, any association between $\bar{X}_{j}, G_{j}$ and $W_{j}$ and the probability of defaulting is solely driven by the association between these former variables and the probability of being of a certain group type.

The unconditional probability of default can, in turn, be written as

$$
\begin{aligned}
\operatorname{Pr}\left(D_{i j}=1\right) & =\operatorname{Pr}\left(D_{i j}=1, T_{j}^{*}=T_{j}^{H}\right)+\operatorname{Pr}\left(D_{i j}=1, T_{j}^{*}=T_{j}^{L}\right) \\
& =\operatorname{Pr}\left(D_{i j}=1 \mid T_{j}^{*}=T_{j}^{H}\right) \operatorname{Pr}\left(T_{j}^{*}=T_{j}^{H}\right)+\operatorname{Pr}\left(D_{i j}=1 \mid T_{j}^{*}=T_{j}^{L}\right) \operatorname{Pr}\left(T_{j}^{*}=T_{j}^{L}\right) .
\end{aligned}
$$

Similarly,

$$
\operatorname{Pr}\left(D_{i j}=0\right)=\operatorname{Pr}\left(D_{i j}=0 \mid T_{j}^{*}=T_{j}^{H}\right) \operatorname{Pr}\left(T_{j}^{*}=T_{j}^{H}\right)+\operatorname{Pr}\left(D_{i j}=0 \mid T_{j}^{*}=T_{j}^{L}\right) \operatorname{Pr}\left(T_{j}^{*}=T_{j}^{L}\right) .
$$

If we further assume that the error terms in equations (3) and (4) have a $F(\cdot)$ and $J(\cdot)$ cumulative distribution function (CDF), respectively, the log likelihood for individual $i$ in group $j$ is given by

$$
\begin{aligned}
\ln l_{i j}= & D_{i j} \ln \left[F\left(\alpha_{H}+X_{i j} \beta_{1, H}+C_{j} \beta_{2, H}\right) J\left(\bar{X}_{j} \delta_{1}+G_{j} \delta_{2}\right)\right. \\
& \left.+F\left(\alpha_{L}+X_{i j} \beta_{1, L}+C_{j} \beta_{2, L}\right)\left(1-J\left(\bar{X}_{j} \delta_{1}+G_{j} \delta_{2}\right)\right)\right] \\
& +\left(1-D_{i j}\right) \ln \left[1-F\left(\alpha_{H}+X_{i j} \beta_{1, H}+C_{j} \beta_{2, H}\right) J\left(\bar{X}_{j} \delta_{1}+G_{j} \delta_{2}\right)\right. \\
& \left.-F\left(\alpha_{L}+X_{i j} \beta_{1, L}+C_{j} \beta_{2, L}\right)\left(1-J\left(\bar{X}_{j} \delta_{1}+G_{j} \delta_{2}\right)\right)\right] .
\end{aligned}
$$

We approximate $F(\cdot)$ and $J(\cdot)$ with a logistic $\mathrm{CDF}^{23}$

\footnotetext{
${ }^{23}$ We also estimated the model using a normal CDF and obtained qualitative similar results.
} 


\section{RESULTS}

We now turn to our estimation results. For comparison purposes, we first report the results using a standard probabilistic regression model, which does not account for unobserved types when modeling the likelihood of default. Table A.3 presents the parameter estimates (and standard errors) of a probit model using three alternative specifications. ${ }^{24}$ The first model only accounts for member and loan characteristics. Although most of the coefficients of the member characteristics generally have the expected signs - in that the variables associated with a low (high) economic status are positively (negatively) correlated with the probability of default - they are generally not statistically significant at conventional levels. We only observe a positive and significant correlation between the probability of default and belonging to a scheduled caste. The loan characteristics, in turn, show a higher correlation with repayment behavior. A larger loan amount, higher interest rate, longer duration, and lower repayment frequency are all associated with a higher probability of default.

The second model adds average (leave-me-out) member characteristics and other group and village controls, which are intended to account for contextual factors that could also affect an individual's repayment decision. Although the positive correlation between the probability of default and belonging to a scheduled caste disappears, a higher proportion of group members of a scheduled caste is associated with a lower repayment probability; the other member characteristics (and the corresponding group averages) remain not significant. The effects of most of the loan characteristics also remain intact.

Several of the other group and village controls exhibit an important association with the probability of default. In particular, having a marketing and insurance program in the group, frequent meetings of group members, and the existence of a financial institution in the village are all positively correlated with the probability of repayment. In contrast, members of groups with a food program, which is distinctive of poorer groups, show a higher probability of default. Finally, in smaller groups (fewer than 13 members), an additional member in the group decreases the individual probability of default, probably due to stronger peer monitoring and pressure effects, whereas in larger groups (13 members or more), the contrary occurs, because coordination, monitoring, and enforcement efforts are probably more difficult to maintain in considerably large groups.

While in the first and second model, we account for the potential correlation in the repayment decision among group members by clustering the error term by group, in the third model, we explicitly control for the potential within-group correlation by estimating a probit model with random effects. Although the inclusion of the random group term in the estimated regression improves the model fit (the within-group correlation is also highly significant), it does not improve the model performance discussed below. Most of the effects of the explanatory variables also remain similar. ${ }^{25}$

As noted earlier, however, all of these models do not account for the unobserved group-type component that is embedded in the error term of the repayment equation and potentially correlated with some of the explanatory variables. Table 5.1 shows the estimation results of the alternative mixture model proposed, which explicitly accounts for unobserved group types when modeling the default behavior of group members. The model allows for two group types (type $H$ and type $L$ ), and the repayment decision is conditional on the unobserved type, where the marginal effects of the member and loan characteristics may vary by type. The average member characteristics and other group and village controls, in turn, help identify the group type.

\footnotetext{
${ }^{24}$ We use a probit model because it provides a better fit and performance than a logit and a linear probability model. Details are available upon request.

${ }^{25}$ In this third model, individuals in groups with a higher proportion of disabled members in the household are also expected to fully repay their loans, and group age is positively correlated with the probability of default (up to groups of 11 years old).
} 
Table 5.1-Probability of default, two-type model

\begin{tabular}{|c|c|c|c|c|}
\hline \multirow[t]{3}{*}{ Variable } & \multicolumn{2}{|c|}{ Type $H$} & \multicolumn{2}{|c|}{ Type $L$} \\
\hline & Coeff. & Std. Error & Coeff. & Std. Error \\
\hline & \multicolumn{4}{|c|}{ Dependent variable: If default } \\
\hline Constant & -3.399 & 0.629 & 7.775 & 28.740 \\
\hline If literate & 0.160 & 0.105 & 0.540 & 0.206 \\
\hline If disabled member in household & 0.258 & 0.163 & -0.263 & 0.383 \\
\hline If owns land & 0.180 & 0.119 & -0.556 & 0.181 \\
\hline If lives in pucca house & -0.198 & 0.122 & -0.997 & 0.186 \\
\hline If lives in kutcha house & 0.022 & 0.124 & -0.844 & 0.209 \\
\hline If self-employed agricultural worker & -0.593 & 0.184 & 1.173 & 0.266 \\
\hline If agricultural laborer & 0.120 & 0.140 & 1.748 & 0.155 \\
\hline If belongs to scheduled tribe or caste & 0.082 & 0.110 & 2.736 & 0.279 \\
\hline If belongs to leading caste & -0.092 & 0.163 & 0.260 & 0.383 \\
\hline Amount of loan ( 1,000 rupees) & 0.068 & 0.016 & 0.462 & 0.049 \\
\hline Number of members with loan & -0.062 & 0.090 & -0.338 & 0.151 \\
\hline Number of members with loan squared & 0.001 & 0.004 & 0.003 & 0.007 \\
\hline Annual interest rate $(\%)$ & 0.083 & 0.013 & 0.277 & 0.034 \\
\hline Length of loan (years) & 0.508 & 0.081 & 0.963 & 0.193 \\
\hline If repayment at least monthly & -0.497 & 0.244 & -10.989 & 30.416 \\
\hline If loan due in 2005 & -1.267 & 0.435 & -0.128 & 0.287 \\
\hline If loan due in 2006 & 1.052 & 0.189 & 1.229 & 0.286 \\
\hline \multicolumn{5}{|l|}{ Probability of type $H$ Group } \\
\hline Constant & -2.901 & 2.501 & & \\
\hline$\%$ literate & 1.921 & 0.409 & & \\
\hline$\%$ disabled member in household & 1.630 & 0.777 & & \\
\hline$\%$ own land & 0.707 & 0.212 & & \\
\hline$\%$ live in pucca house & -1.124 & 0.276 & & \\
\hline$\%$ live in kutcha house & -1.052 & 0.228 & & \\
\hline$\%$ self-employed agricultural worker & 0.697 & 0.323 & & \\
\hline$\%$ agricultural laborer & 1.902 & 0.318 & & \\
\hline$\%$ belong to scheduled tribe or caste & 0.623 & 0.167 & & \\
\hline$\%$ belong to leading caste & -1.020 & 0.496 & & \\
\hline Age of group (years) & 0.025 & 0.066 & & \\
\hline Age of group squared & -0.004 & 0.004 & & \\
\hline If group has food credit program & -0.951 & 0.115 & & \\
\hline If group has marketing program & 1.688 & 0.277 & & \\
\hline If group has insurance program & 0.443 & 0.139 & & \\
\hline If group meets at least monthly & 3.105 & 0.223 & & \\
\hline If located in Telangana & 2.320 & 0.255 & & \\
\hline If located in Rayalaseema & 0.652 & 0.211 & & \\
\hline
\end{tabular}


Table 5.1-Continued

\begin{tabular}{|c|c|c|c|}
\hline \multirow[t]{3}{*}{ Variable } & \multicolumn{2}{|c|}{ Type $H$} & Type $L$ \\
\hline & Coeff. & Std. Error & Std. Error \\
\hline & \multicolumn{3}{|c|}{ Dependent variable: If default } \\
\hline Number of group members & 0.132 & 0.360 & \\
\hline Number of group members squared & -0.014 & 0.014 & \\
\hline If financial institution in village & 0.979 & 0.139 & \\
\hline If public bus in village & 0.139 & 0.117 & \\
\hline If telephone in village & 1.076 & 0.168 & \\
\hline If post office in village & -0.684 & 0.130 & \\
\hline \multicolumn{4}{|l|}{$\begin{array}{l}\text { Predicted probability of being type } \\
H \text { group }\end{array}$} \\
\hline Average & & & $79.8 \%$ \\
\hline Groups, no members defaulting & & & $82.9 \%$ \\
\hline Groups, all members defaulting & & & $66.9 \%$ \\
\hline Groups, some members defaulting & & & $76.4 \%$ \\
\hline \multicolumn{4}{|l|}{$\begin{array}{l}\text { Predicted individual default } \\
\text { probability }\end{array}$} \\
\hline Average & & & $19.6 \%$ \\
\hline Conditional on being in type $H$ group & & & $9.5 \%$ \\
\hline Conditional on being in type $L$ group & & & $62.8 \%$ \\
\hline \# observations & & & 12,883 \\
\hline Log-likelihood & & & $-5,111.6$ \\
\hline
\end{tabular}

Source: Authors' own calculations.

Several important patterns emerge from Table 5.1. First, the conditional probability of default is considerably different between the two group types, as reported at the bottom of the table. More specifically, the estimated probability of default conditional on being in a group of type $H$ individuals is 9.5 percent versus 62.8 percent in a group of type $L$ individuals. Hence, the model clearly distinguishes between two group types: type $H$ is likely composed of "responsible" individuals with probably high levels of effort and/or effective monitoring and enforcement rules who are more likely to repay their loans, whereas type $L$ is composed of "irresponsible" individuals with probably low levels of effort and/or less effective monitoring and enforcement rules who are less likely to repay their loans. Similarly, the average probability of being a type $H$ group is roughly 80 percent in our sample; interestingly, groups in which all members pay back their loans exhibit a higher probability of being a type $H$ group than any other groups. ${ }^{26}$ In particular, for groups in which none of the members defaulted, the likelihood of being a type $H$ group is 82.9 percent, versus 76.4 percent for groups in which some members defaulted, and 66.9 percent for groups in which all members defaulted. These results further support the identification of seeming "responsible" and "irresponsible" groups by our model.

An analysis of the factors used to describe the probability of being in a type $H$ group also indicates that "responsible" groups are more likely characterized, for example, by women who are literate, own some portion of land, live in semi-pucca houses, are related to agricultural activities, and belong to a scheduled tribe but not necessarily to a leading caste. Similarly, responsible groups are more likely to hold frequent meetings of its members, to have a marketing and insurance program but not a

\footnotetext{
${ }^{26}$ Recall that in our raw data, we observe full repayment by all members in 76 percent of the groups; in another 17 percent of the groups, all members default.
} 
food credit program for its members, and to have access to additional services in the village such as financial institutions and telephones. Microfinance institutions should probably look for these characteristics when trying to identify potential responsible groups or areas in which to operate or expand. Holding frequent meetings appears to be particularly important, as we further detail below. This is in line with other studies that suggest that, in addition to facilitating peer monitoring and enforcement, frequent group meetings may directly increase social contact and reduce lending risks (Gine and Karlan 2009; Feigenberg, Field, and Pande 2011). ${ }^{27}$ The existence of other programs (such as marketing and insurance programs) in the group could also stimulate social cooperation and strengthen social ties, in addition to providing additional services to members, thereby increasing the risk sharing among members. ${ }^{28}$

Figure A.3 provides additional support to the correct identification of "responsible" and "irresponsible" groups by our model, based on the observed behavior patterns in the data. For example, the probability of being a type $H$ ("responsible") group is positively correlated with the proportion of literate women in the group. A closer look at the data shows that among groups in which more than half of the women in the group are literate, there is a higher proportion of groups with no members defaulting (82 percent) and a lower proportion of groups with all members defaulting (13 percent), as compared with groups in which fewer than half of the women are literate (76 and 17 percent, respectively). The differences are more pronounced when comparing the distribution of intragroup default behavior between groups with high and low frequencies of meetings. Among groups that at least hold monthly meetings, which is also distinctive of type $H$ groups, the proportions of groups with no members defaulting and all members defaulting are 80 and 14 percent, respectively; among groups that hold meetings less than once a month, the corresponding proportions are 48 and 41 percent. Similar patterns are observed when comparing groups with and without marketing programs and with and without a financial institution in the village, which are also correlated with the likelihood of being a type $H$ group in the model. These findings suggest that several of the factors included in the type-probability equation help identify potential group types and that the types in the model are not purely identified by functional form.

Another important pattern that emerges from Table 5.1 is the difference in direction, magnitude, and statistical significance of several of the parameter estimates in the default equation between the two group types. This pattern suggests that the factors driving individual repayment behavior may vary by type. Table 5.2 shows the conditional marginal effects for the different individual and loan characteristics included in the repayment equation after accounting for group type. ${ }^{29} \mathrm{We}$ do not observe major changes in the probability of default among type $H$ group members after a change in most of the individual covariates; for example, being a self-employed agricultural worker and living in pucca houses decrease the probability of default by roughly 3 and 1 percentage points, whereas owning some portion of land increases the likelihood of defaulting by less than 1 percent. Among type $L$ group members, in contrast, being a self-employed agricultural worker increases the probability of default by 14 percentage points; being an agricultural laborer also substantially increases the likelihood of defaulting by 29 percentage points, as well as belonging to a scheduled caste (31 percentage points). Owning some portion of land or living in either pucca or kutcha houses (as compared with living in semi-pucca houses), in turn, decrease the probability of default by $8-16$ percentage points.

\footnotetext{
${ }^{27}$ Gine and Karlan (2009) found that groups with stronger social networks are less likely to experience default problems after removing joint liability. Feigenberg, Field, and Pande (2011) showed that repeated interactions can facilitate cooperation by allowing individuals to sustain reciprocal economic ties.

${ }^{28}$ Fearon, Humphreys, and Weinstein (2009) and Feigenberg, Field, and Pande (2011) also showed, in different settings, the importance of community development programs to encourage social cohesion.

${ }^{29}$ The normal-based confidence intervals reported for the estimated marginal effects are based on 200 bootstrap replications and are bias corrected. Although not reported, the bootstrap means are similar to the estimated marginal effects, which support the bootstrap procedure implemented.
} 
Table 5.2-Conditional marginal effects (percentage points)

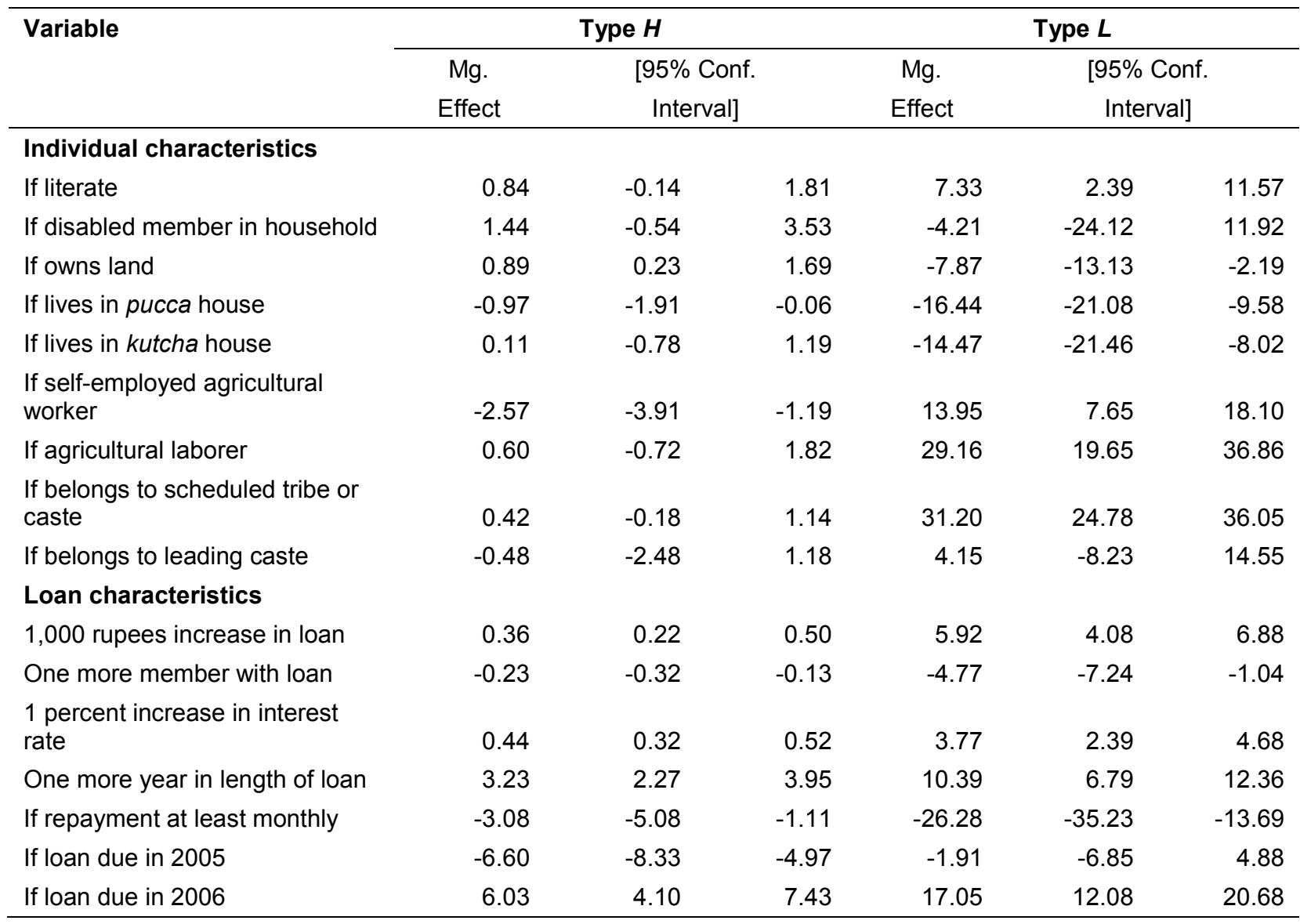

Source: Authors' own calculations.

Note: The marginal effects are calculated at the means of the covariates. For continuous variables, the corresponding change is indicated in the table. For discrete variables, the change is from 0 to 1 . The confidence intervals reported are normal based and bias corrected using 200 bootstrap replications.

Regarding the loan covariates, monthly (or higher) repayment frequencies and an additional member receiving a loan decrease the likelihood of defaulting by 3 and 0.2 percentage points, respectively among type $H$ group members; among type $L$ group members, the corresponding decrease is of 26 and 5 percentage points, respectively. An increase in the loan amount, interest rate, and loan duration also results in a much higher increase in the probability of default among type $L$ group members than among type $H$ group members.

These varying effects by type can help lenders better assess their clients and understand the factors driving client behavior. Land ownership, housing conditions, labor activities, and belonging to a scheduled tribe seem to matter among type $L$ groups, in contrast with type $H$ groups, where the effects (if any) are much more limited. The loan characteristics are also more relevant for type $L$ groups than for type $H$ groups. These differences have important policy implications and can help lending institutions reduce their transaction costs. Field and Pande (2008), for example, pointed out the important trade-off between imposing higher repayment frequencies (a standard practice among microfinance institutions to encourage fiscal discipline and reduce default risk) and the substantial increase in transaction costs of installment collection. Field and Pande (2008) found that switching to lower-frequency repayment schedules could allow lenders to significantly reduce their transaction costs, with virtually no increase in client default, particularly among first-time borrowers. Our results suggest that the fiscal discipline imposed by frequent repayment is critical among groups suspected (or with a higher probability) of being 
type $L$ groups, but not among type $H$ groups, where less costly repayment schedules could be implemented. The cost savings are likely higher than the (marginal) increase in the default rate in type $H$ groups. Encouraging longer-term investments through higher loan terms also seems more reasonable among type $H$ groups, which could improve the borrowers' repayment capacity in the long run (in a similar way as a more flexible repayment schedule).

The parameter estimates in the two-type model are also different from those obtained under a standard probabilistic regression, which does not allow for unobserved consumer types. To better appreciate these differences, Table 5.3 reports the unconditional marginal effects on the probability of default for all the variables included in the regression analysis for the probit and two-type model specifications. ${ }^{30}$ In the full two-type model (last column of Table 5.3), the average member characteristics and other group and village characteristics affect the likelihood of defaulting through the probability of being in a type $H$ (or "responsible") group. A direct comparison between the full probit model and the two-type model reveals that the two models produce different marginal effects. ${ }^{31}$ For example, being an agricultural laborer or belonging to a scheduled caste increases the overall probability of default by roughly 4 percentage points in the two-type model (all else equal), whereas in the probit model, the change in probability is not significant; a similar pattern is observed for the condition of living in pucca houses or being self-employed agricultural workers, which both decrease the overall probability of default by 3 and 1 percentage points in the type-varying model and which are not significant in the probit model. Similarly, monthly (or higher) repayment frequencies will decrease the likelihood of defaulting by 6 percentage points in the two-type model and by 7 percentage points in the probit model, whereas an additional year in the length of the loan will increase the likelihood of defaulting by 4 percentage points in the first model and by more than 8 percentage points in the second model. Interestingly, an additional member in a group seems to increase the probability of default in the type-varying model, whereas in the probit model, the converse is true, at least in smaller groups. It seems that the stronger peer monitoring and pressure effects do not necessarily outweigh the higher coordination costs of having additional members in the group.

Table 5.3-Unconditional marginal effects (percentage points)

\begin{tabular}{lccccccccc}
\hline Variable & \multicolumn{3}{c}{ Probit Model } & \multicolumn{2}{c}{ Full Probit Model } & \multicolumn{2}{c}{ Two-Type Model } \\
\cline { 2 - 11 } & $\begin{array}{c}\text { Mg. } \\
\text { Effect }\end{array}$ & $\begin{array}{c}\text { [95\% Conf. } \\
\text { Interval] }\end{array}$ & $\begin{array}{c}\text { Mg. } \\
\text { Effect }\end{array}$ & $\begin{array}{c}\text { [95\% Conf. } \\
\text { Interval] }\end{array}$ & $\begin{array}{c}\text { Mg. } \\
\text { Effect }\end{array}$ & $\begin{array}{c}\text { [95\% Conf. } \\
\text { Interval] }\end{array}$ \\
\hline $\begin{array}{l}\text { Individual characteristics } \\
\text { If literate }\end{array}$ & -0.81 & -2.01 & 0.51 & -0.18 & -1.84 & 1.58 & 1.56 & 0.54 & 2.50 \\
$\begin{array}{l}\text { If disabled member in } \\
\text { household }\end{array}$ & -1.62 & -4.01 & 0.72 & -0.04 & -3.15 & 3.21 & 0.82 & -1.45 & 2.76 \\
If owns land & -0.84 & -1.71 & 0.27 & 0.18 & -1.37 & 2.18 & -0.08 & -0.80 & 0.76 \\
If lives in pucca house & -0.37 & -1.48 & 0.64 & -0.73 & -2.86 & 1.22 & -2.68 & -3.67 & -1.50 \\
If lives in kutcha house & 2.82 & 1.43 & 4.26 & -0.11 & -2.30 & 2.19 & -1.50 & -2.74 & -0.20 \\
If self-employed agricultural & -0.37 & -2.09 & 1.02 & 0.04 & -3.25 & 2.76 & -0.74 & -2.13 & 0.51 \\
worker & 0.76 & -0.67 & 2.02 & 0.59 & -2.12 & 3.16 & 3.76 & 2.30 & 5.03 \\
If agricultural laborer & & & & & & & & & \\
If belongs to scheduled & 6.10 & 5.40 & 6.83 & -1.98 & -5.35 & 1.17 & 3.83 & 2.38 & 5.33 \\
tribe or caste & 3.12 & 1.06 & 4.76 & -0.23 & -3.37 & 2.05 & 0.03 & -1.94 & 1.51 \\
If belongs to leading caste & & & & & & & & & \\
\hline
\end{tabular}

${ }^{30}$ The marginal effects of the probit model with random effects, excluded from the table, are qualitatively similar (though smaller) to those of the full probit model. For comparison purposes, the confidence intervals of the marginal effects for all models were derived using 200 bootstrap replications.

${ }^{31}$ Note that the marginal effects decrease as we move across the two probit model specifications, for the variables they can be compared. 
Table 5.3-Continued

\begin{tabular}{|c|c|c|c|c|c|c|c|c|c|}
\hline \multirow{2}{*}{$\begin{array}{l}\text { Variable } \\
\text { Loan characteristics }\end{array}$} & \multicolumn{3}{|c|}{ Probit Model } & \multicolumn{3}{|c|}{ Full Probit Model } & \multicolumn{3}{|c|}{ Two-Type Model } \\
\hline & $\begin{array}{c}\text { Mg. } \\
\text { Effect }\end{array}$ & \multicolumn{2}{|c|}{$\begin{array}{l}\text { [95\% Conf. } \\
\text { Interval] }\end{array}$} & $\begin{array}{l}\text { Mg. } \\
\text { Effect }\end{array}$ & \multicolumn{2}{|c|}{$\begin{array}{l}\text { [95\% Conf. } \\
\text { Interval] }\end{array}$} & $\begin{array}{l}\text { Mg. } \\
\text { Effect }\end{array}$ & \multicolumn{2}{|c|}{$\begin{array}{l}\text { [95\% Conf. } \\
\text { Interval] }\end{array}$} \\
\hline 1,000 rupees increase in loan & 1.60 & 1.46 & 1.76 & 1.45 & 1.30 & 1.63 & 0.97 & 0.77 & 1.11 \\
\hline One more member with loan & 0.01 & -0.14 & 0.16 & 0.15 & -0.06 & 0.34 & -0.74 & -0.95 & -0.37 \\
\hline 1 percent increase in interest rate & 1.19 & 1.13 & 1.26 & 1.37 & 1.30 & 1.45 & 0.81 & 0.65 & 0.89 \\
\hline $\begin{array}{l}\text { One more year in length of } \\
\text { loan }\end{array}$ & 7.90 & 7.47 & 8.26 & 8.31 & 7.90 & 8.69 & 4.02 & 3.21 & 4.48 \\
\hline If repayment at least monthly & -14.03 & -15.83 & -12.55 & -6.78 & -8.28 & -5.51 & -5.65 & -7.60 & -3.39 \\
\hline If loan due in 2005 & -6.01 & -6.59 & -5.36 & -5.84 & -6.44 & -5.14 & -6.08 & -7.17 & -4.85 \\
\hline If loan due in 2006 & 9.52 & 8.90 & 10.18 & 10.64 & 9.97 & 11.35 & 7.25 & 5.55 & 8.39 \\
\hline \multicolumn{10}{|l|}{$\begin{array}{l}\text { Average member } \\
\text { characteristics }\end{array}$} \\
\hline $10-\%$ increase literate & & & & 0.00 & -0.21 & 0.21 & -1.34 & -1.66 & -1.04 \\
\hline $10-\%$ increase disabled member & & & & -0.94 & -1.35 & -0.56 & -1.15 & -1.64 & -0.56 \\
\hline $10-\%$ increase own land & & & & -0.51 & -0.74 & -0.33 & -0.52 & -0.80 & -0.28 \\
\hline $10-\%$ increase pucca house & & & & -0.12 & -0.33 & 0.12 & 0.88 & 0.60 & 1.13 \\
\hline $10-\%$ increase $k u t c h a$ house & & & & 0.45 & 0.20 & 0.68 & 0.82 & 0.46 & 1.25 \\
\hline $\begin{array}{l}10-\% \text { increase self-employed } \\
\text { ag. worker }\end{array}$ & & & & 0.12 & -0.19 & 0.48 & -0.51 & -0.92 & -0.05 \\
\hline $\begin{array}{l}10-\% \text { increase agricultural } \\
\text { laborer }\end{array}$ & & & & 0.18 & -0.11 & 0.47 & -1.33 & -1.64 & -1.01 \\
\hline $\begin{array}{l}10-\% \text { increase scheduled tribe } \\
\text { or caste }\end{array}$ & & & & 0.75 & 0.42 & 1.11 & -0.46 & -0.72 & -0.28 \\
\hline $10-\%$ increase leading caste & & & & 0.49 & 0.24 & 0.85 & 0.80 & 0.29 & 1.53 \\
\hline \multicolumn{10}{|l|}{$\begin{array}{l}\text { Other group and village } \\
\text { characteristics }\end{array}$} \\
\hline One more year of age of group & & & & 1.19 & 1.03 & 1.36 & 0.06 & -0.21 & 0.37 \\
\hline If group has food credit program & & & & 8.08 & 7.67 & 8.57 & 8.46 & 4.94 & 13.33 \\
\hline If group has marketing program & & & & -6.12 & -6.49 & -5.76 & -8.36 & -9.43 & -7.51 \\
\hline If group has insurance program & & & & -5.29 & -5.75 & -4.88 & -3.07 & -4.50 & -2.20 \\
\hline If group meets at least monthly & & & & -30.11 & -30.88 & -29.49 & -44.59 & -47.40 & -42.51 \\
\hline If located in Telangana & & & & -9.58 & -10.03 & -9.13 & -18.01 & -22.78 & -13.68 \\
\hline If located in Rayalaseema & & & & -2.79 & -3.32 & -2.28 & -4.27 & -5.33 & -3.02 \\
\hline One more member in group & & & & -1.41 & -1.63 & -1.15 & 1.27 & 0.60 & 1.73 \\
\hline If financial institution in village & & & & -6.01 & -6.39 & -5.65 & -6.59 & -8.22 & -5.45 \\
\hline If public bus in village & & & & 1.19 & 0.83 & 1.59 & -1.06 & -1.72 & -0.12 \\
\hline If telephone in village & & & & -3.43 & -3.83 & -3.01 & -9.96 & -11.56 & -8.18 \\
\hline If post office in village & & & & 0.97 & 0.66 & 1.34 & 4.85 & 3.89 & 6.31 \\
\hline
\end{tabular}

Source: Authors' own calculations.

Note: The marginal effects are calculated at the means of the covariates. For continuous variables, the corresponding change is indicated in the table. For discrete variables, the change is from 0 to 1 . The confidence intervals reported are normal based and bias corrected using 200 bootstrap replications. 
The two models, however, also show the importance of frequent meetings among group members in keeping individuals from falling behind in their loan repayments (probably resulting in better peer monitoring and pressure and/or higher social interactions). In particular, in groups where members meet at least on a monthly basis, the individual probability of default is 30 percentage points lower in the probit model and 45 percentage points lower in the type-varying model than in groups where members meet less frequently. Both models also suggest the importance of promoting marketing and insurance programs among group members, which are negatively correlated with defaulting, and the inverse for subsidized food credit programs, which are distinctive of poorer groups. The existence of a financial institution and a telephone in the village is also highly correlated with a positive repayment behavior under the two models.

Overall, the results indicate the importance of having a flexible, type-consistent model, which allows for varying effects by type and which provides better insight about the possible factors affecting members' repayment behavior. The proposed model can also help lenders better identify and screen potential clients, as we further discuss below.

\section{Predictive Performance}

We now analyze whether allowing for different group types yields better out-of-sample predictions for the probability of default. We want to examine whether the proposed type-varying model has a higher predictive power than standard probabilistic methods, as this may help reduce information asymmetries in microlending and aid lenders in correctly identifying and selecting current and future clients (groups). To conduct the performance assessment, we follow a standard cross-validation procedure and randomly partition our dataset into a design sample for model estimation (60 percent of the observations) and a test sample for further analysis ( 40 percent of the observations). The partition is conducted at the group level, and both samples maintain the population proportions of default and nondefault actions.

Table 5.4 provides performance indicators for the different models estimated. ${ }^{32}$ The indicators include the average predicted default probability, the mean square predicted error, and several performance indicators based on converting the estimated default probabilities to a binary regime prediction using the standard 0.5 rule (that is, if the estimated default probability is greater or equal to 0.5 , the individual is predicted to default, whereas if the estimated probability is less than 0.5 , the individual is predicted to not default). For the two-type model, the performance assessment is based on two alternative calculations of the probability of default. In general, a lender could evaluate granting a loan based on the estimated unconditional probability of default or based on the conditional probability of default, depending on the likelihood of being in a group of a certain type. Hence, different mixtures for estimating the probability of default could be used.

\footnotetext{
${ }^{32}$ The results are based on 200 repeated 60-40 percent partitions. The results are also not sensitive to alternative data partitions (70-30 percent and 50-50 percent).
} 
Table 5.4—Predictive performance of alternative models

\begin{tabular}{|c|c|c|c|c|}
\hline Indicator & $\begin{array}{l}\text { Probit } \\
\text { Model }\end{array}$ & $\begin{array}{c}\text { Full } \\
\text { Probit } \\
\text { Model }\end{array}$ & $\begin{array}{l}\text { Two-Type } \\
\text { Naive }\end{array}$ & $\begin{array}{l}\text { Two-Type } \\
\text { Conservative }\end{array}$ \\
\hline & \multicolumn{4}{|c|}{ Out-of-sample performance $(5,068$ obs.) } \\
\hline Average predicted default probability (observed $=0.210$ ) & 0.185 & 0.186 & 0.199 & 0.237 \\
\hline Mean square predicted error & 0.160 & 0.159 & 0.145 & 0.156 \\
\hline Predictive performance & $73.7 \%$ & $74.7 \%$ & $76.4 \%$ & $76.0 \%$ \\
\hline Correct default/nondefault classification & $77.9 \%$ & $77.9 \%$ & $79.2 \%$ & $78.6 \%$ \\
\hline $\begin{array}{l}\text { Correct default classification (sensitivity), } \\
1,062 \text { defaults }\end{array}$ & $2.2 \%$ & $17.2 \%$ & $21.9 \%$ & $31.3 \%$ \\
\hline $\begin{array}{l}\text { Correct nondefault classification (specificity), } \\
4,006 \text { nondefaults }\end{array}$ & $98.0 \%$ & $94.0 \%$ & $94.4 \%$ & $91.2 \%$ \\
\hline
\end{tabular}

Source: Authors' own calculations.

Note: The naive approach is based on the unconditional probability of default of each individual. The conservative approach uses the probability of default based on the probability of an individual being in a particular group type. The performance and classification rates are based on converting the estimated default probabilities to a binary regime prediction using the standard 0.5 rule. The predictive performance measure is based on McFadden, Puig, and Kirschner (1977); the measure is equal to $p_{11}+p_{22}-p_{12}^{2}-p_{21}^{2}$, where $p_{i j}$ is the $i j$ th entry in the standard $2 \times 2$ confusion matrix of actual versus predicted $(0,1)$ outcomes in which the entries are expressed as a fraction of the sum of all entries. Sensitivity accounts for the percentage of cases in which individuals defaulting are also predicted to default, whereas specificity measures the percentage of cases in which individuals not defaulting are also predicted to not default. The results are based on 200 repeated $60-40 \%$ data partitions (averages reported).

The two approaches considered are:

1. A naive type-consistent approach that only uses the unconditional probability of default, such that,

$$
\begin{aligned}
\operatorname{Pr}\left(D_{i j}=1\right) & =F\left(\alpha_{H}+X_{i j} \beta_{1, H}+C_{j} \beta_{2, H}\right) J\left(\bar{X}_{j} \delta_{1}+G_{j} \delta_{2}\right) \\
& +F\left(\alpha_{L}+X_{i j} \beta_{1, L}+C_{j} \beta_{2, L}\right)\left(1-J\left(\bar{X}_{j} \delta_{1}+G_{j} \delta_{2}\right)\right) .
\end{aligned}
$$

2. A conservative type-consistent approach, which takes into account the likelihood of being in a type $H$ group. In particular,

$$
\operatorname{Pr}\left(D_{i j}=1\right)= \begin{cases}F\left(\alpha_{H}+X_{i j} \beta_{1, H}+C_{j} \beta_{2, H}\right) & \text { if } \operatorname{Pr}\left(T_{j}^{*}=T_{j}^{H}\right) \text { in upper quintile } \\ F\left(\alpha_{H}+X_{i j} \beta_{1, H}+C_{j} \beta_{2, H}\right) J\left(\bar{X}_{j} \delta_{1}+G_{j} \delta_{2}\right) & \\ +F\left(\alpha_{L}+X_{i j} \beta_{1, L}+C_{j} \beta_{2, L}\right)\left(1-J\left(\bar{X}_{j} \delta_{1}+G_{j} \delta_{2}\right)\right) & \text { if } \operatorname{Pr}\left(T_{j}^{*}=T_{j}^{H}\right) \text { in 2nd - 4th quintile } \\ F\left(\alpha_{L}+X_{i j} \beta_{1, L}+C_{j} \beta_{2, L}\right) & \text { if } \hat{\operatorname{Pr}}\left(T_{j}^{*}=T_{j}^{H}\right) \text { in lower quintile }\end{cases}
$$

where $\operatorname{Pr}\left(T_{j}^{*}=T_{J}^{H}\right)$ is the estimated probability of being in a type $H$ group. ${ }^{33}$

As shown in the table, the naive approach produces a mean default probability (19.9 percent) that is closer to the observed sample mean of 21 percent than the full probit model (18.6 percent) and the conservative approach (23.7 percent). The naive and conservative approach also report a lower mean

\footnotetext{
${ }^{33}$ This approach is in line with Gan and Mosquera (2008), who examined unobserved consumer types in the Ecuadorian credit card market.
} 
squared prediction error than the probit model ( 0.145 and 0.156 , respectively, versus 0.159$)$. The two type-consistent approaches also show a higher overall predictive performance based on the McFadden, Puig, and Kirschner (1977) standard measure. ${ }^{34}$ In particular, the naive approach has a predictive performance of 76.4 percent, and the conservative approach has a predictive performance of 76 percent, as compared with 74.7 percent of the probit model. The poorer performance of the probit model is largely explained by its lower correct default classification rate (that is, identification of "bad" borrowers): 17.2 percent versus 21.9 percent of the naive approach and 31.3 percent of the conservative approach.

Regarding the correct nondefault classification rate (that is, identification of good borrowers), the probit model performs better than the conservative approach but poorer than the naive approach.

An alternative way of evaluating the out-of-sample performance is to examine the number of good clients that the model rates as "bad" (Type I error) and the number of bad clients that the model rates as "good" (Type II error) for varying cutoff values of the probability of default. In Table 5.4, we used the standard 0.5 rule for the performance assessment. Figures 5.1 and 5.2 compare the percentage of good borrowers rejected and the percentage of bad borrowers accepted across the probit, naive, and conservative type-consistent approaches for different cutoff values. In the case of Type I errors, the naive approach and the probit model outperform the conservative approach for most of the cutoff values. More specifically, for cutoff values above 0.1 , the lending institution will do better in identifying good" clients by relying on the naive approach or probit model. In the case of Type II errors, however, both the naive and conservative approaches outperform the probit model for basically the entire range of cutoff values, and for values above 0.3 , the conservative approach has a considerably higher (and increasing) performance than the naive approach. For sufficiently lenient acceptance rules (cutoff values above 0.5), the differences in the percentage of bad accepted between the conservative approach and the other models are in the order of 10-23 percentage points.

Figure 5.1-Comparison of Type I errors

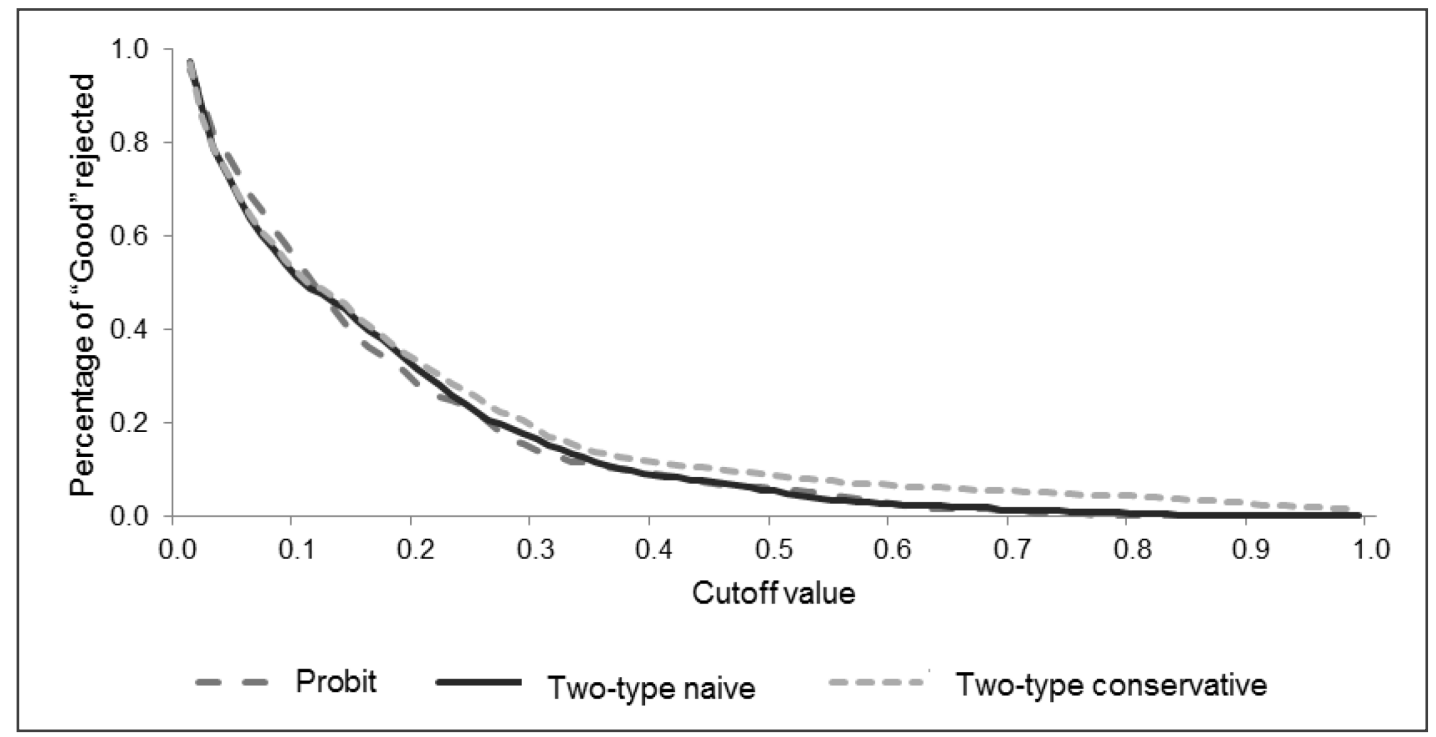

Source: Authors' own calculations.

Note: The naive approach is based on the unconditional probability of default of each individual. The conservative approach uses the probability of default based on the probability of an individual being in a particular group type. The results are based on 200 repeated $60-40 \%$ data partitions (averages reported).

${ }^{34}$ McFadden, Puig, and Kirschner's (1977) overall performance measure is equal to $p_{11}+p_{22}-p_{12}^{2}-p_{21}^{2}$, where $p_{i j}$ is the $i j$ th entry (expressed as a fraction of the sum of all entries) in the $2 \times 2$ confusion matrix of actual versus predicted $(0,1)$ outcomes using the 0.5 rule. 
Figure 5.2-Comparison of Type II errors

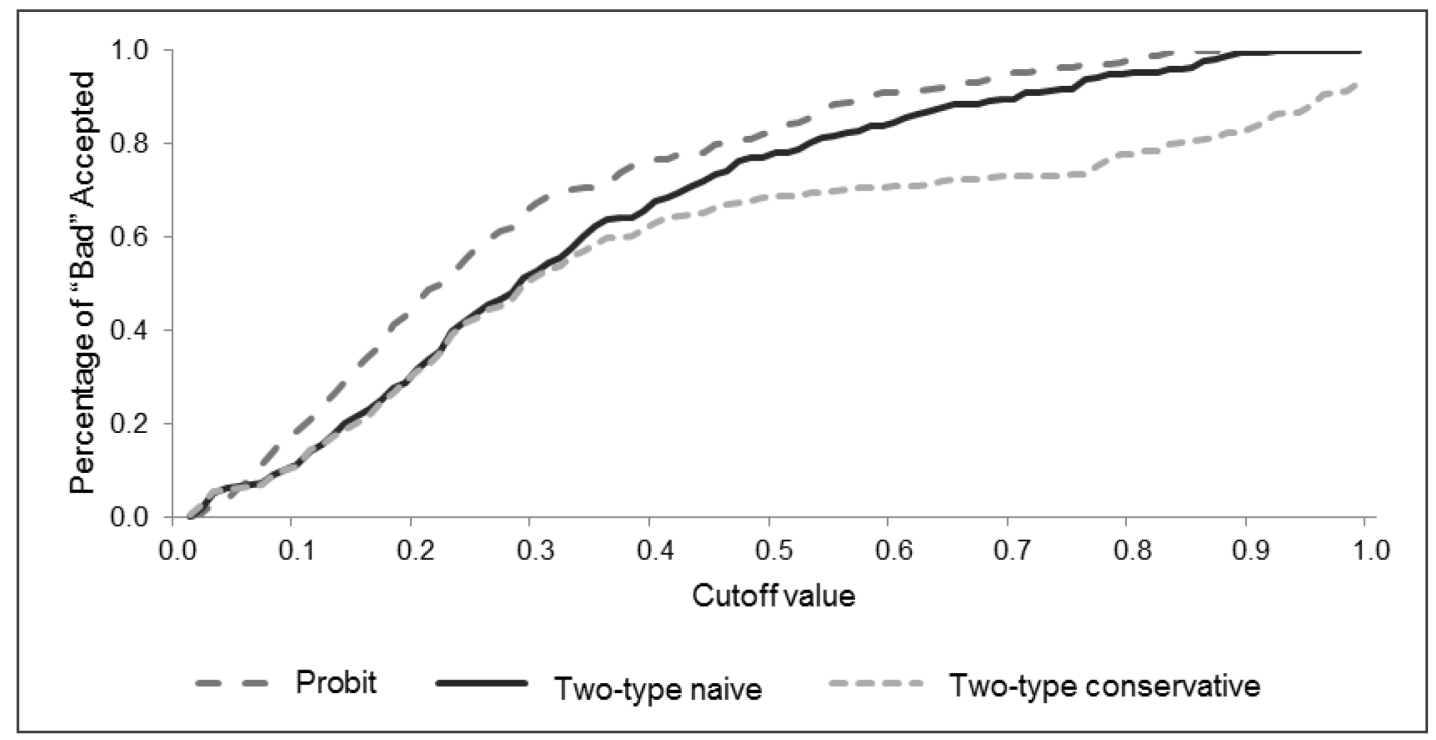

Source: Authors' own calculations.

Note: The naive approach is based on the unconditional probability of default of each individual. The conservative approach uses the probability of default based on the probability of an individual being in a particular group type. The results are based on 200 repeated $60-40 \%$ data partitions (averages reported).

Hence, we generally attain a higher predictive power when allowing for unobserved group types when modeling the probability of default of group members, as compared with a standard probabilistic regression model. If the lending institution is more interested in minimizing the number of "bad" clients (classified as "good" by the model), then the lender should probably follow a conservative approach; however, if the lender is more interested in identifying "good" clients (classified as "bad" by the model), it should follow a naive approach. The probit model will also perform well for the latter. Yet, for more lenient acceptance rules, using a naive approach or probit model will also result in a much higher acceptance rate of bad clients relative to the conservative approach. For example, for a cutoff value of 0.4 , the naive approach outperforms the conservative approach by 3 percentage points in terms of the rejection rate of good clients, whereas the conservative approach outperforms the naive approach by a similar degree in terms of the acceptance rate of bad clients. However, for a cutoff value of 0.6 , the naive approach outperforms the conservative approach by 4 percentage points when identifying good clients, whereas the conservative approach outperforms the naive approach by 14 percentage points when identifying bad clients. 


\section{CONCLUDING REMARKS}

This paper proposes an empirical model to address the potential omitted variable problem resulting from group lending with unobserved types. We use a mixture model to explicitly account for group types when modeling the repayment behavior of group members. In the model, individuals make repayment decisions based on their unobserved group type, as well as on observable individual and loan characteristics. Average member characteristics and other group and village characteristics help identify the group types. We also allow the marginal effects in the repayment equation to vary across types.

The estimation results support our model specification and show the advantages of relying on a type-consistent method when examining the probability of default of group members. First, the model clearly distinguishes two group types: an apparent "responsible" group with a low probability of default among group members and an "irresponsible" group with a high probability of default. Second, we find important differences in the marginal effects of the different individual and loan characteristics included in the repayment equation across group types. Third, the type-varying model shows a higher predictive performance than standard probabilistic models. From a policy perspective, our model helps to better understand the underlying factors driving repayment behavior, which appear to differ across groups. These differences can aid lenders when designing loan contracts for different types of clients. Similarly, the model can help lenders attenuate information asymmetries in microlending by aiding them in correctly classifying potential clients. A more accurate risk-scoring tool is essential to reduce the high transaction costs faced by microfinance institutions. It can also prevent including potential bad borrowers and excluding good borrowers from sensitive microcredit markets in developing regions.

Finally, it is worth noting that the analysis has focused on a two-type model given the nature of our data. The apparent two types may result from a combination of factors, including peer selection, peer monitoring and pressure, and other unobserved factors such as social cohesion. However, disentangling these effects is beyond the scope of the study. Certainly, there can be a wider set of types in other contexts, and the proposed method can be easily adapted to allow for additional types. Considerably increasing the number of types, however, may require imposing restrictions on the value of the coefficients in the repayment equation (for example, not necessarily allowing for different marginal effects across all types) in order to avoid a highly parameterized model, which could be difficult to estimate in practice. Our analysis also follows a discrete treatment of the repayment decision given the observed behavior of most borrowers in the sample (either full repayment or no payment). Yet, the model can be adapted to instead examine the percentage of loans repaid by members. Future research should attempt to incorporate dynamic aspects in the repayment decisions of members under a type-varying setting. 


\section{APPENDIX A: SUPPLEMENTARY TABLES AND FIGURES}

Table A.1-Data description

\begin{tabular}{|c|c|}
\hline Variable & Description \\
\hline Default & If member failed to fully repay loan \\
\hline Literate & If member can read and write \\
\hline Disabled & If any household member has a disability \\
\hline Owns land & If member owns any land \\
\hline Pucca house & If member lives in a house made of stone, bricks, concrete, or timber \\
\hline Kutcha house & If member lives in a house made of hay, grass, mud, or bamboo \\
\hline Self-employed & If member is self-employed agricultural worker \\
\hline Agricultural laborer & If member provides agricultural labor for someone else \\
\hline Scheduled tribe or caste & If member belongs to a scheduled tribe or caste \\
\hline Leading caste & If member belongs to a leading caste \\
\hline Age of group & Group age in years \\
\hline Food credit program & If group members receive a food credit program \\
\hline Marketing program & If group members are provided with a marketing program \\
\hline Insurance program & If group members are provided with an insurance program \\
\hline Group meets at least monthly & If group members meet at least on a monthly basis \\
\hline Located in Telangana & If the group is located in Telangana \\
\hline Located in Rayalaseema & If the group is located in Rayalaseema \\
\hline Located in Coastal Andhra & If the group is located in Coastal Andhra \\
\hline Number of group members & Number of members in the group \\
\hline Financial institution in village & If there is a financial institution in the village \\
\hline Public bus in village & If public bus service is available in the village \\
\hline Telephone in village & If telephone service is available in the village \\
\hline Post office in village & If there is a post office in the village \\
\hline Amount of loan & Amount of loan borrowed by member, in rupees \\
\hline Number of members with loan & Number of members in the group who borrowed loan \\
\hline Annual interest rate & Annual interest rate of the loan \\
\hline Length of loan & Length of the loan, in years \\
\hline Monthly repayment frequency & If repayment frequency of the loan at least monthly \\
\hline Loan due in 2004 & If loan is due in 2004 \\
\hline Loan due in 2005 & If loan is due in 2005 \\
\hline Loan due in 2006 & If loan is due in 2006 \\
\hline
\end{tabular}

Source: Authors' own calculations. 
Table A.2-Sorting based on observables

If intragroup variance is less than or equal to intravillage or intramandal variance by member characteristic

\begin{tabular}{lrrrr}
\hline & \multicolumn{2}{c}{ Intravillage } & \multicolumn{2}{c}{ Intramandal } \\
\cline { 2 - 5 } & \# groups & $\begin{array}{r}\text { \% total } \\
\text { groups }\end{array}$ & \# groups & \% total \\
If literate & 538 & 56.0 & 646 & groups \\
If disabled member in household & 636 & 66.3 & 727 & 65.7 \\
If owns land & 606 & 63.1 & 755 & 68.2 \\
If lives in pucca house & 591 & 61.6 & 746 & 67.4 \\
If lives in kutcha house & 627 & 65.3 & 768 & 69.4 \\
If self-employed agricultural worker & 761 & 79.3 & 866 & 78.2 \\
If agricultural laborer & 703 & 73.2 & 863 & 78.0 \\
If belongs to scheduled tribe or caste & 863 & 89.9 & 1018 & 92.0 \\
If belongs to leading caste & 680 & 70.8 & 763 & 68.9 \\
Average & & & & \\
\hline
\end{tabular}

Source: Authors' own calculations.

Note: The intravillage comparisons exclude 150 villages where there is only one group in the village, whereas the intramandal comparisons exclude 3 mandals.

Table A.3 - Probability of default, one-type model

\begin{tabular}{|c|c|c|c|c|c|c|}
\hline \multirow[t]{3}{*}{ Variable } & \multicolumn{2}{|c|}{ Probit Model } & \multicolumn{2}{|c|}{$\begin{array}{c}\text { Probit Model } \\
\text { Full }\end{array}$} & \multicolumn{2}{|c|}{$\begin{array}{l}\text { Random-Effects } \\
\text { Probit Model }\end{array}$} \\
\hline & Coeff. & Std. Err. & Coeff. & Std. Err. & Coeff. & Std. Err. \\
\hline & \multicolumn{6}{|c|}{ Dependent variable: If default } \\
\hline Constant & -1.827 & 0.562 & 0.502 & 1.370 & 0.646 & 2.121 \\
\hline If literate & -0.032 & 0.055 & -0.007 & 0.020 & 0.039 & 0.118 \\
\hline If disabled member in household & -0.065 & 0.080 & -0.002 & 0.032 & -0.030 & 0.194 \\
\hline If owns land & -0.033 & 0.071 & 0.008 & 0.026 & 0.010 & 0.139 \\
\hline If lives in pucca house & -0.015 & 0.082 & -0.031 & 0.037 & -0.189 & 0.149 \\
\hline If lives in kutcha house & 0.107 & 0.086 & -0.005 & 0.047 & 0.056 & 0.152 \\
\hline If self-employed agricultural worker & -0.014 & 0.119 & 0.002 & 0.077 & 0.212 & 0.221 \\
\hline If agricultural laborer & 0.030 & 0.089 & 0.025 & 0.056 & 0.247 & 0.173 \\
\hline If belongs to scheduled tribe or caste & 0.229 & 0.094 & -0.085 & 0.113 & 0.300 & 0.298 \\
\hline If belongs to leading caste & 0.128 & 0.081 & -0.009 & 0.036 & 0.288 & 0.204 \\
\hline Amount of loan (1,000 rupees) & 0.061 & 0.016 & 0.059 & 0.018 & 0.071 & 0.021 \\
\hline Number of members with loan & 0.009 & 0.072 & 0.065 & 0.095 & 0.126 & 0.195 \\
\hline Number of members with loan squared & 0.000 & 0.003 & -0.003 & 0.005 & -0.003 & 0.010 \\
\hline Annual interest rate (percent) & 0.046 & 0.014 & 0.056 & 0.015 & 0.182 & 0.024 \\
\hline Length of loan (years) & 0.274 & 0.108 & 0.304 & 0.113 & 0.867 & 0.168 \\
\hline If repayment at least monthly & -0.460 & 0.249 & -0.256 & 0.269 & -0.463 & 0.423 \\
\hline If loan due in 2005 & -0.235 & 0.156 & -0.247 & 0.163 & -0.803 & 0.286 \\
\hline If loan due in 2006 & 0.359 & 0.158 & 0.430 & 0.170 & 1.138 & 0.275 \\
\hline
\end{tabular}


Table A.3-Continued

\begin{tabular}{|c|c|c|c|c|c|c|}
\hline \multirow[t]{3}{*}{ Variable } & \multicolumn{2}{|c|}{ Probit Model } & \multicolumn{2}{|c|}{$\begin{array}{l}\text { Probit Model } \\
\text { Full } \\
\end{array}$} & \multicolumn{2}{|c|}{$\begin{array}{l}\text { Random-Effects } \\
\text { Probit Model }\end{array}$} \\
\hline & Coeff. & Std. Err. & Coeff. & Std. Err. & Coeff. & Std. Err. \\
\hline & \multicolumn{6}{|c|}{ Dependent variable: If default } \\
\hline$\%$ literate & & & 0.000 & 0.237 & -0.034 & 0.448 \\
\hline$\%$ disabled member in household & & & -0.405 & 0.426 & -1.730 & 0.987 \\
\hline$\%$ own land & & & -0.220 & 0.178 & -0.467 & 0.325 \\
\hline$\%$ live in pucca house & & & -0.051 & 0.190 & 0.050 & 0.353 \\
\hline$\%$ live in kutcha house & & & 0.189 & 0.216 & 0.584 & 0.380 \\
\hline$\%$ self-employed agricultural worker & & & 0.050 & 0.259 & -0.143 & 0.471 \\
\hline$\%$ agricultural laborer & & & 0.074 & 0.188 & -0.310 & 0.337 \\
\hline$\%$ belong to scheduled tribe or caste & & & 0.310 & 0.160 & 0.337 & 0.356 \\
\hline$\%$ belong to leading caste & & & 0.206 & 0.334 & 0.338 & 0.583 \\
\hline Age of group (years) & & & 0.076 & 0.074 & 0.299 & 0.109 \\
\hline Age of group squared & & & -0.003 & 0.004 & -0.012 & 0.006 \\
\hline If group has food credit program & & & 0.319 & 0.108 & 0.910 & 0.172 \\
\hline If group has marketing program & & & -0.288 & 0.144 & -0.775 & 0.236 \\
\hline If group has insurance program & & & -0.238 & 0.118 & -0.513 & 0.193 \\
\hline If group meets at least monthly & & & -0.952 & 0.144 & -2.935 & 0.203 \\
\hline If located in Telangana & & & -0.409 & 0.141 & -1.140 & 0.227 \\
\hline If located in Rayalaseema & & & -0.122 & 0.154 & -0.490 & 0.247 \\
\hline Number of group members & & & -0.346 & 0.204 & -0.933 & 0.331 \\
\hline Number of group members squared & & & 0.013 & 0.008 & 0.033 & 0.013 \\
\hline If financial institution in village & & & -0.266 & 0.116 & -0.765 & 0.189 \\
\hline If public bus in village & & & 0.051 & 0.103 & 0.152 & 0.166 \\
\hline If telephone in village & & & -0.140 & 0.119 & -0.250 & 0.186 \\
\hline If post office in village & & & 0.041 & 0.109 & 0.147 & 0.171 \\
\hline $\ln \left(\sigma^{2} u\right)$ & & & & & 2.836 & 0.103 \\
\hline Rho & & & & & 0.945 & 0.005 \\
\hline Predicted default probability & & $19.5 \%$ & & $19.5 \%$ & & $7.6 \%$ \\
\hline \# observations & & 12,883 & & 12,883 & & 12,883 \\
\hline Log-likelihood & & -5776.26 & & -5237.50 & & -1121.56 \\
\hline
\end{tabular}

Source: Authors' own calculations.

Note: The standard errors reported in the probit model are robust, clustered by group. The $\ln (\mathrm{u} u$ ) term in the random-effects model represents the group-level variance component, and Rho captures the proportion of the total variance contributed by the group-level variance component. 
Figure A.1-Histogram of percentage of loan repaid by member

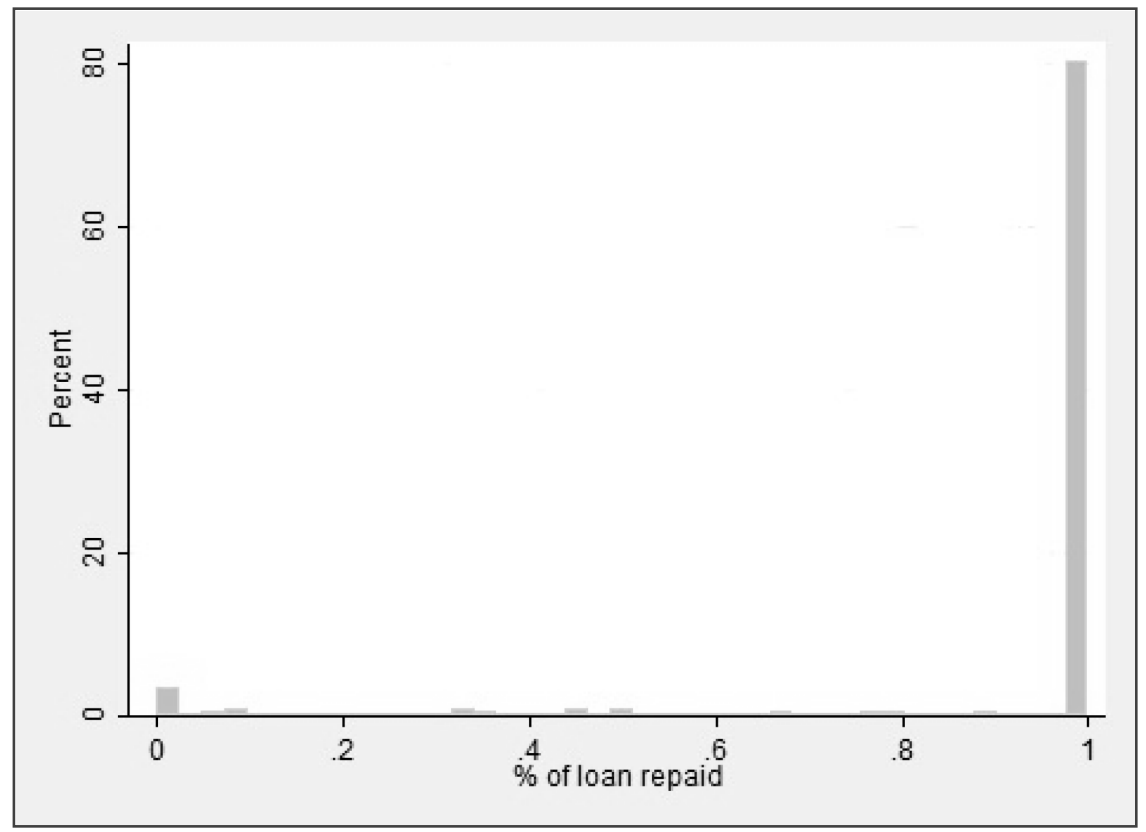

Source: Authors' own calculations.

Figure A.2-Location of villages in Andhra Pradesh and group default behavior

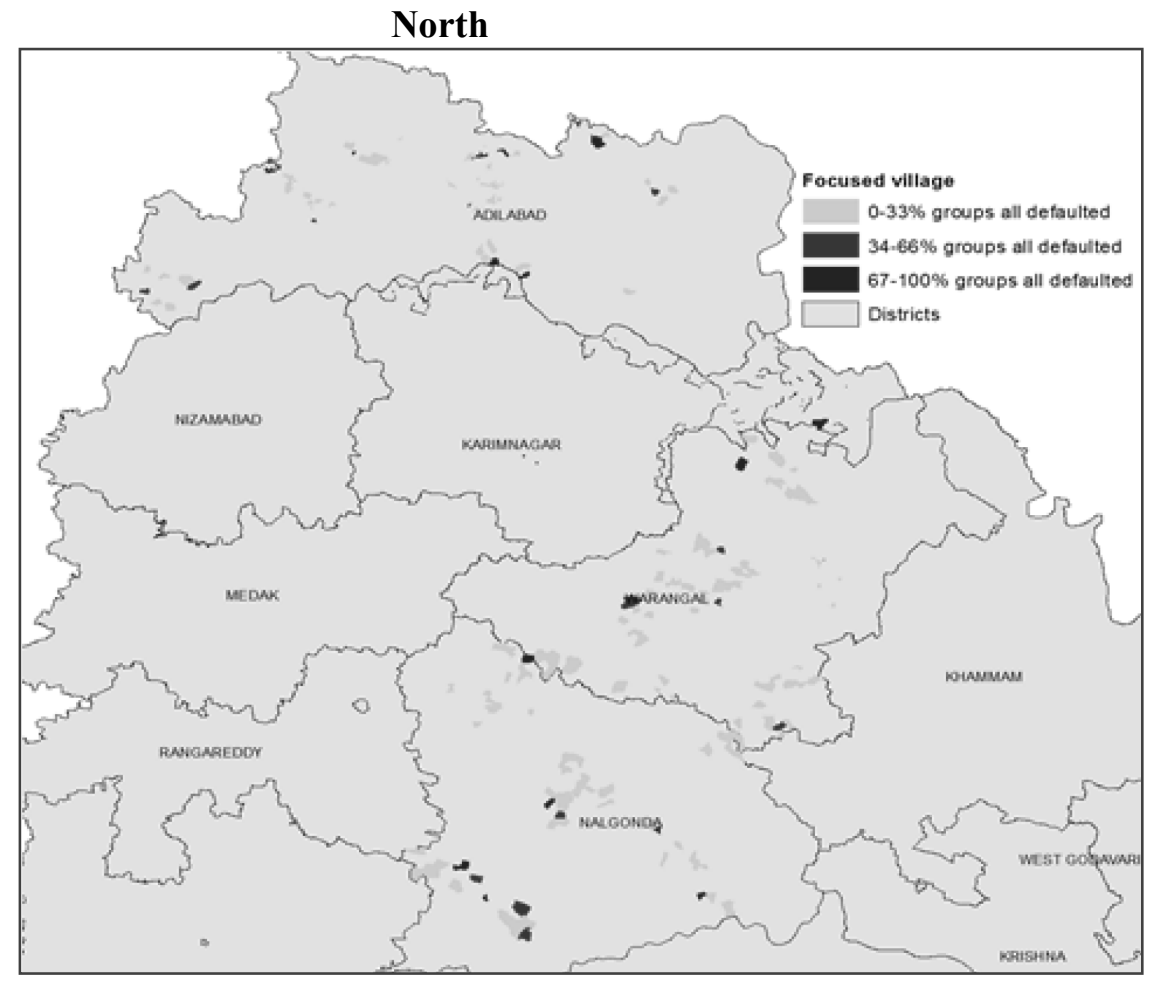


Figure A.2-Continued

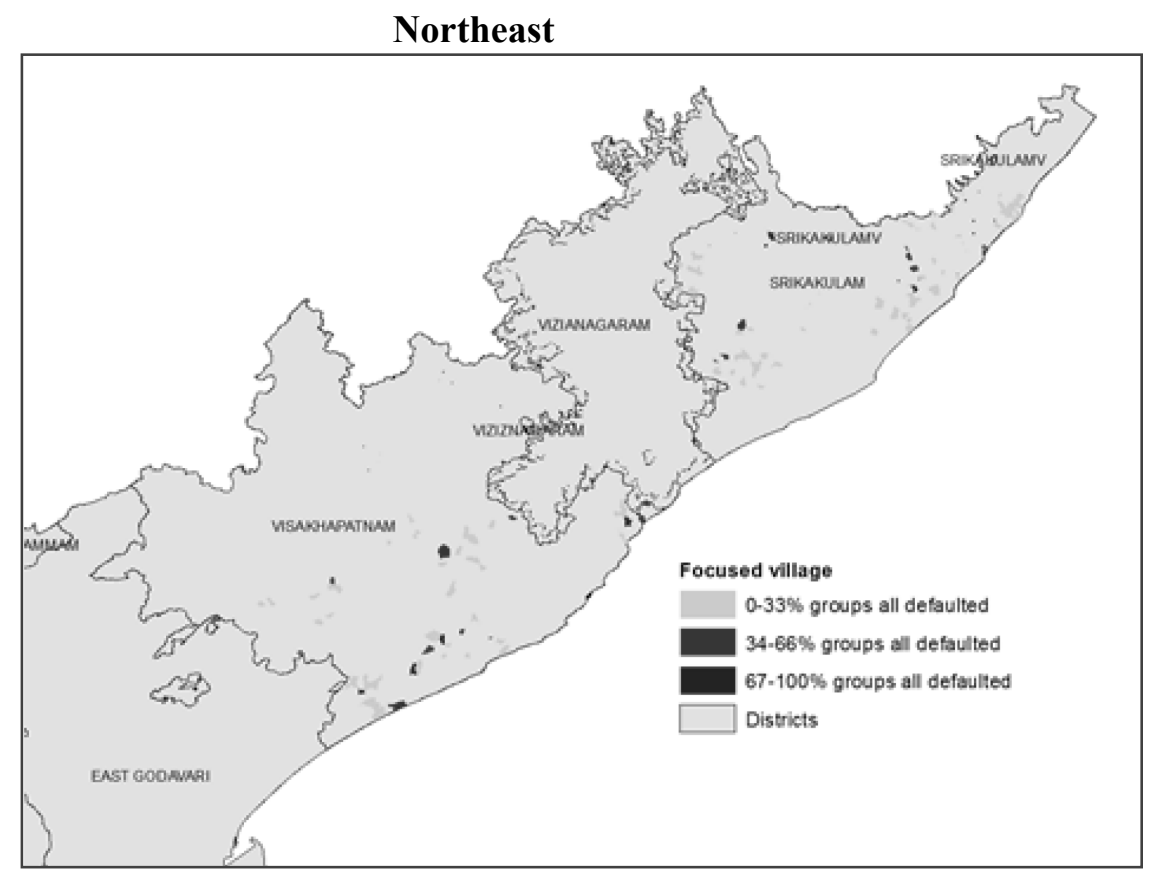

South

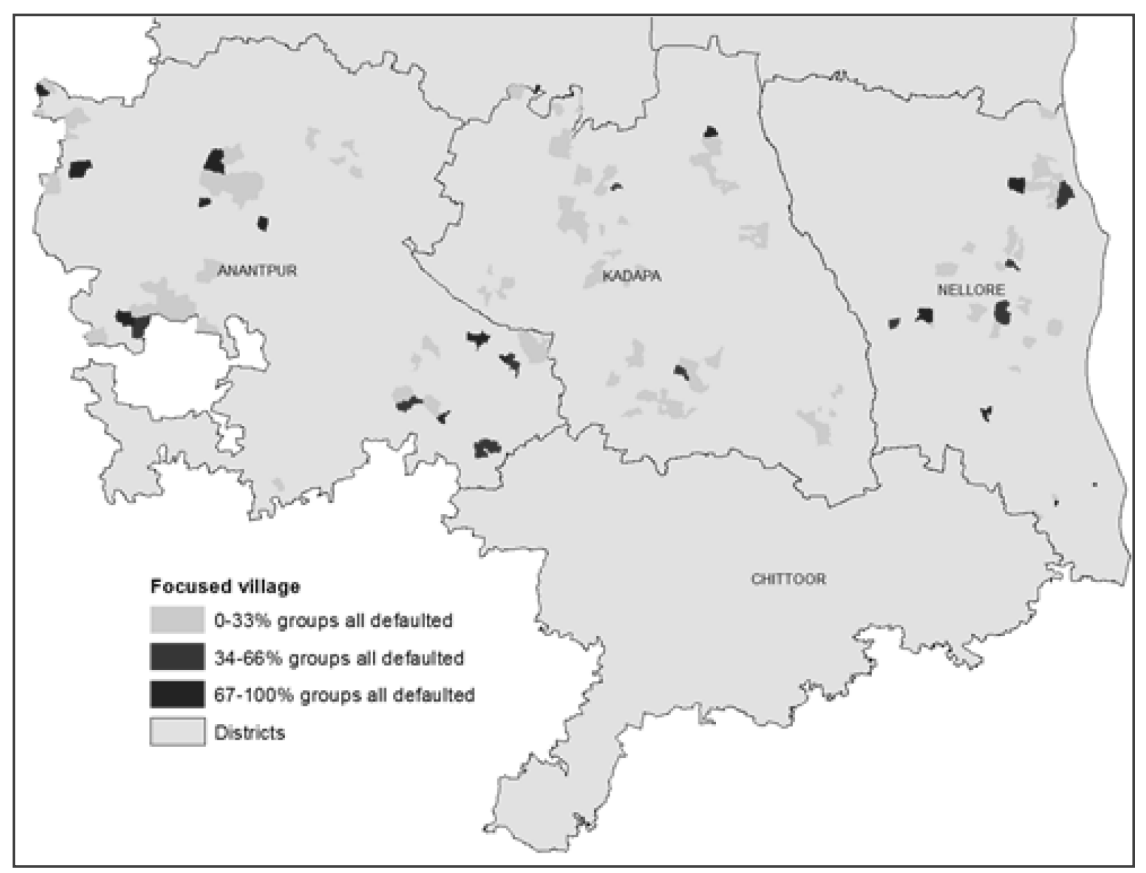

Source: Authors' own calculations. 
Figure A.3-Distribution of intragroup default behavior by different group characteristics
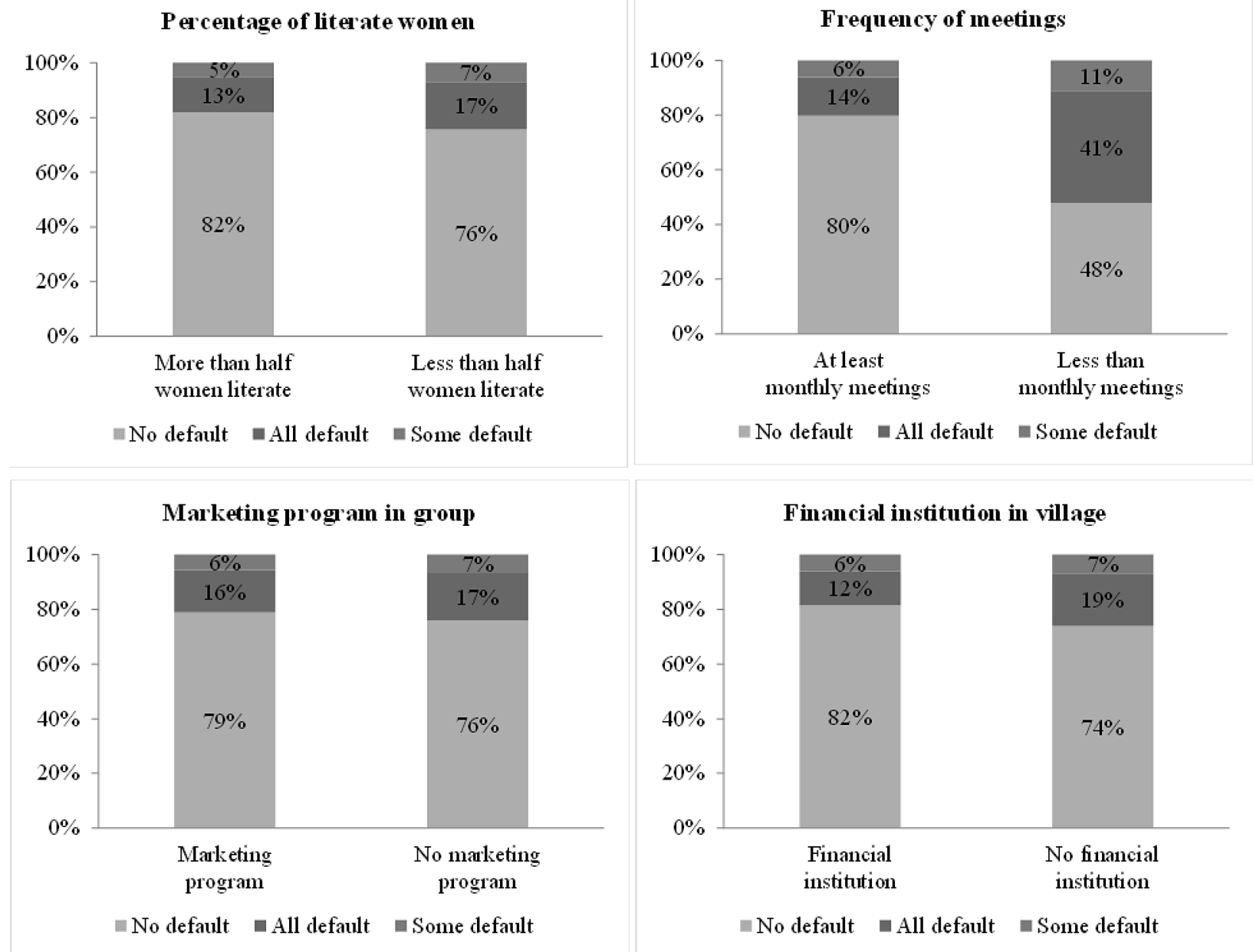

Source: Authors' own calculations. 


\section{APPENDIX B: SOLUTION TO THE MODEL WITH PEER SELECTION AND MORAL HAZARD}

In this appendix, we solve the model with peer selection and moral hazard outlined in Section 2. The model is an extension of Ghatak's (1999) basic model, in which we allow borrowers to vary on their risk type and effort level. The model setup is presented in Section 2. We also assume that $Y>r+q$-that is, a successful borrower can make a profit even when her partner loses. This assumption is innocuous because if it does not hold, a borrower with a failed project may have a higher payoff than one with a successful project, which is an unreasonable scenario. We consider both a noncooperative game scenario, in which each borrower maximizes her own payoff, and a cooperative game scenario, in which matched borrowers maximize the total payoff of their group. given by

In the noncooperative game setting, the maximization problems of the matched borrowers are

$$
\begin{aligned}
& \max _{e_{i}} E \pi_{i j}=\left(p_{i}+e_{i}\right) Y-\left(p_{i}+e_{i}\right) r-q\left(p_{i}+e_{i}\right)\left(1-p_{j}-e_{j}\right)-1 / 2 \gamma e_{i}^{2} \\
& \max _{e_{j}} E \pi_{j i}=\left(p_{j}+e_{j}\right) Y-\left(p_{j}+e_{j}\right) r-q\left(p_{j}+e_{j}\right)\left(1-p_{i}-e_{i}\right)-1 / 2 \gamma e_{j}^{2} \\
& \text { s.t. } e_{i} \geq 0, \quad e_{j} \geq 0
\end{aligned}
$$

The first order conditions (FOCs) are:

$$
\begin{aligned}
& \partial E \pi_{i j} / \partial e_{i}=Y-r-q\left(1-p_{j}-e_{j}\right)-\gamma e_{i} \leq 0 \\
& \partial E \pi_{j i} / \partial e_{j}=Y-r-q\left(1-p_{i}-e_{i}\right)-\gamma e_{j} \leq 0 \\
& e_{i} \geq 0 \\
& e_{j} \geq 0 \\
& e_{i}\left[Y-r-q\left(1-p_{j}-e_{j}\right)-\gamma e_{i}\right]=0 \\
& e_{j}\left[Y-r-q\left(1-p_{i}-e_{i}\right)-\gamma e_{j}\right]=0 .
\end{aligned}
$$

Solving the FOCs, we have

$$
\begin{aligned}
& e_{i j}^{*}=0, \text { if } \gamma \leq q \\
& e_{i j}^{*}=\frac{(\gamma+q)(Y-r)-q\left[q\left(1-p_{i}\right)+\gamma\left(1-p_{j}\right)\right]}{\gamma^{2}-q^{2}} \text { if } \gamma>q .
\end{aligned}
$$

We change the subindex of effort from $i$ to $i j$, because the optimal effort of borrower $i$ depends not only on her own type but also on the type of her partner. To eliminate the corner solution under which the second-order condition (SOC) is violated, we assume $\gamma>q$. Hereafter we only consider the interior solution. We note that the SOC of the internal solution is satisfied, and we have

$$
e_{b b}^{*}>e_{a b}^{*}>e_{b a}^{*}>e_{a a}^{*} \text {. }
$$


This result suggests that a borrower's optimal effort level is higher if she is a safe type and/or if her partner is a safe type.

Substituting $e_{i j}^{*}$ into $E \pi_{i j}$ and denoting $M, A$, and $B$ as

$$
\begin{aligned}
& M=Y-r-q, \\
& A=e_{b b}^{*}-e_{b a}^{*}=e_{a b}^{*}-e_{a a}^{*}=\frac{\gamma q\left(p_{b}-p_{a}\right)}{\gamma^{2}-q^{2}}, \\
& B=e_{b a}^{*}-e_{a a}^{*}=e_{b b}^{*}-e_{a b}^{*}=\frac{q^{2}\left(p_{b}-p_{a}\right)}{\gamma^{2}-q^{2}},
\end{aligned}
$$

we obtain

$$
\begin{aligned}
E \pi_{b b}^{*}-E \pi_{b a}^{*} & =A M+q p_{b}\left(p_{b}-p_{a}\right)+q p_{b} B+q\left(e_{b b} p_{b}-e_{b a} p_{a}+e_{b b}^{2}-e_{b a} e_{a b}\right)-0.5 \gamma A\left(e_{b b}+e_{b a}\right) \\
& >A M+q p_{b}\left(p_{b}-p_{a}\right)+q p_{b} B+q e_{b b}\left(p_{b}-p_{a}\right)-(\gamma-q) A e_{b b} \\
& =A M+q p_{b}\left(p_{b}-p_{a}\right)+q p_{b} B+q^{2}\left(p_{b}-p_{a}\right) e_{b b} /(\gamma+q)>0,
\end{aligned}
$$

and

$$
\begin{aligned}
E \pi_{a b}^{*}-E \pi_{a a}^{*} & =A M+q p_{a}\left(p_{b}-p_{a}\right)+q p_{a} B+q\left(e_{a b} p_{b}-e_{a a} p_{a}-e_{a a}^{2}+e_{b a} e_{a b}\right)-0.5 \gamma A\left(e_{a b}+e_{a a}\right) \\
& >A M+q p_{a}\left(p_{b}-p_{a}\right)+q p_{a} B+q e_{a b}\left(p_{b}-p_{a}\right)-(\gamma A-q B) e_{a b} \\
& =A M+q p_{b}\left(p_{b}-p_{a}\right)+q p_{b} B>0 .
\end{aligned}
$$

These results suggest that a borrower prefers a safer partner regardless of her own type.

We then examine whether positive assortative matching is the only equilibrium. Following Ghatak (2009), such equilibrium must satisfy the optimal sorting property (Becker 1993). In other words, the net expected loss for a safe borrower of having a risky borrower is higher than the net expected gain for a risky borrower of having a safe partner. Therefore, a risky borrower does not have sufficient incentives to pay enough money to a safe borrower to match with her. We find

$$
\begin{aligned}
\left(E \pi_{b b}^{*}-E \pi_{b a}^{*}\right)-\left(E \pi_{a b}^{*}-E \pi_{a a}^{*}\right) & =q\left(p_{b}-p_{a}\right)^{2}+2 q\left(p_{b}-p_{a}\right) B-\gamma A B+q\left(e_{b b}^{2}+e_{a a}^{2}-2 e_{b a} e_{a b}\right) \\
& =q \gamma^{4}\left(p_{b}-p_{a}\right)^{2} /\left(\gamma^{2}-q^{2}\right)^{2}>0 .
\end{aligned}
$$

Consistent with Proposition 1 in Ghatak (1999), this result suggests that positive assortative matching is the only equilibrium.

Next, we keep the same model setup but assume a cooperative game setting in which matched borrowers maximize their joint payoff given by

$$
\begin{aligned}
\max _{e_{i}, e_{j}}\left(E \pi_{i j}+E \pi_{j i}\right. & =\left(p_{i}+e_{i}\right) Y-\left(p_{i}+e_{i}\right) r-q\left(p_{i}+e_{i}\right)\left(1-p_{j}-e_{j}\right)-1 / 2 \gamma e_{i}^{2} \\
& +\left(p_{j}+e_{j}\right) Y-\left(p_{j}+e_{j}\right) r-q\left(p_{j}+e_{j}\right)\left(1-p_{i}-e_{i}\right)-1 / 2 \gamma e_{j}^{2}
\end{aligned}
$$

s.t. $e_{i} \geq 0, \quad e_{j} \geq 0$ 
The FOCs are

$$
\begin{aligned}
& \partial E \pi_{i j} / \partial e_{i}=Y-r-q+2 q\left(p_{j}+e_{j}\right)-\gamma e_{i} \leq 0 \\
& \partial E \pi_{j i} / \partial e_{j}=Y-r-q+2 q\left(p_{i}+e_{i}\right)-\gamma e_{j} \leq 0 \\
& e_{i} \geq 0 \\
& e_{j} \geq 0 \\
& e_{i}\left[Y-r-q+2 q\left(p_{j}+e_{j}\right)-\gamma e_{i}\right]=0 \\
& e_{j}\left[Y-r-q+2 q\left(p_{i}+e_{i}\right)-\gamma e_{j}\right]=0 .
\end{aligned}
$$

Solving the FOCs, we have

$$
\begin{aligned}
& e_{i j}^{*}=0 \text { if } \gamma \leq 2 q \\
& e_{i j}^{*}=\frac{\left.(\gamma+2 q)(Y-r-q)+2 q\left[2 q p_{i}+\gamma p_{j}\right)\right]}{\gamma^{2}-4 q^{2}} \text { if } \gamma>2 q
\end{aligned}
$$

We impose the assumption $\gamma>2 q$ to eliminate the corner solution. For the interior solution, the SOC is satisfied. Similar to the noncooperative game, we obtain

$$
e_{b b}^{*}>e_{a b}^{*}>e_{b a}^{*}>e_{a a}^{*}
$$

We next prove that a group with two safe borrowers has a higher joint payoff than a group with one safe borrower and one risky borrower. Plugging $e_{i j}^{*}$ into $E \pi_{i j}$, we have

$$
\begin{aligned}
& E \pi_{b b}^{*}-E \pi_{b a}^{*}=A^{\prime} M+q p_{b}\left(p_{b}-p_{a}\right)+q p_{b} B^{\prime}+q\left(e_{b b} p_{b}-e_{b a} p_{a}\right)+q\left(e_{b b}^{2}-e_{b a} e_{a b}\right)-0.5 \gamma\left(e_{b b}^{2}-e_{b a}^{2}\right), \\
& E \pi_{b b}^{*}-E \pi_{a b}^{*}=B^{\prime} M+\left(p_{b}-p_{a}\right) M+q p_{b}\left(p_{b}-p_{a}\right)+q\left(2 p_{b} e_{b b}-p_{a} e_{b a}-p_{a} e_{a b}\right)+q\left(e_{b b}^{2}-e_{b a} e_{a b}\right)-0.5 \gamma\left(e_{b b}^{2}-e_{a b}^{2}\right), \\
& A^{\prime}=e_{b b}^{*}-e_{b a}^{*}=e_{a b}^{*}-e_{a a}^{*}=\frac{2 \gamma q\left(p_{b}-p_{a}\right)}{\gamma^{2}-4 q^{2}}, B^{\prime}=e_{b a}^{*}-e_{a a}^{*}=e_{b b}^{*}-e_{a b}^{*}=\frac{4 q^{2}\left(p_{b}-p_{a}\right)}{\gamma^{2}-4 q^{2}} .
\end{aligned}
$$

where

We note

$$
\begin{aligned}
& q\left(e_{b b}^{2}-e_{b a} e_{a b}\right)-0.5 \gamma\left(e_{b b}^{2}-e_{b a}^{2}\right)+q\left(e_{b b}^{2}-e_{b a} e_{a b}\right)-0.5 \gamma\left(e_{b b}^{2}-e_{a b}^{2}\right) \\
> & 2 q\left(e_{b b}^{2}-e_{b a}^{2}-e_{a b}^{2}\right)-\gamma e_{b b}^{2}+0.5 \gamma\left(e_{a b}^{2}+e_{b a}^{2}\right) \\
= & -0.5(\gamma-2 q) A\left(e_{b b}+e_{b a}\right)-0.5(\gamma-2 q) B\left(e_{b b}+e_{a b}\right) \\
> & -(\gamma-2 q)(A+B) e_{b b}=-(A+B) M-2 q p_{b}(A+B) .
\end{aligned}
$$


Then,

$$
\begin{aligned}
& 2 E \pi_{b b}^{*}-\left(E \pi_{a b}^{*}+E \pi_{b a}^{*}\right) \\
> & (A+B) M+2 q p_{b}\left(p_{b}-p_{a}\right)+\left(p_{b}-p_{a}\right) M+q p_{b} B+q\left(e_{b b} p_{b}-e_{b a} p_{a}\right)+ \\
& +q\left(2 p_{b} e_{b b}-p_{a} e_{b a}-p_{a} e_{a b}\right)-(A+B) M-2 q p_{b}(A+B) \\
= & 2 q p_{b}\left(p_{b}-p_{a}\right)+\left(p_{b}-p_{a}\right) M+q\left(e_{b b} p_{b}-e_{b a} p_{a}\right)+q\left(2 p_{b} e_{b b}-p_{a} e_{b a}-p_{a} e_{a b}\right)-2 q p_{b} A-q p_{b} B \\
> & 2 q p_{b}\left(p_{b}-p_{a}\right)+\left(p_{b}-p_{a}\right) M+q p_{b} A+q p_{b} A+q p_{b} B-2 q p_{b} A-q p_{b} B \\
= & 2 q p_{b}\left(p_{b}-p_{a}\right)+\left(p_{b}-p_{a}\right) M>0
\end{aligned}
$$

Therefore, a safe borrower will prefer a safe borrower to a risky borrower.

We finally examine whether positive assortative matching is the only equilibrium, which is implied by

$$
2 E \pi_{b b}+2 E \pi_{a a}-2\left(E \pi_{b a}+E \pi_{a b}\right)>0
$$

We have

$$
\begin{aligned}
E \pi_{b b}+E \pi_{a a}-\left(E \pi_{b a}+E \pi_{a b}\right) & =\left(E \pi_{b b}^{*}-E \pi_{b a}^{*}\right)-\left(E \pi_{a b}^{*}-E \pi_{a a}^{*}\right) \\
& =q\left(p_{b}-p_{a}\right)^{2}+2 q\left(p_{b}-p_{a}\right) B^{\prime}-\gamma A^{\prime} B^{\prime}+q\left(e_{b b}^{2}+e_{a a}^{2}-2 e_{b a} e_{a b}\right) \\
& =q\left(p_{b}-p_{a}\right)^{2}+B^{\prime}\left[2 q\left(p_{b}-p_{a}\right)-\gamma A^{\prime}\right]+\frac{4 q^{5}\left(\gamma^{2}+4 q^{2}\right)\left(p_{b}-p_{a}\right)^{2}}{\left(\gamma^{2}-4 q^{2}\right)^{2}} \\
& =q\left(p_{b}-p_{a}\right)^{2}-\frac{32 q^{5}\left(p_{b}-p_{a}\right)^{2}}{\left(\gamma^{2}-4 q^{2}\right)^{2}}+\frac{4 q^{5}\left(\gamma^{2}+4 q^{2}\right)\left(p_{b}-p_{a}\right)^{2}}{\left(\gamma^{2}-4 q^{2}\right)^{2}} \\
& =q\left(p_{b}-p_{a}\right)^{2}\left[1+\frac{-32 q^{4}+\left(\gamma^{2}+4 q^{2}\right) 4 q^{2}}{\left(\gamma^{2}-4 q^{2}\right)^{2}}\right] \\
& =q \gamma^{2}\left(p_{b}-p_{a}\right)^{2} /\left(\gamma^{2}-4 q^{2}\right)>0
\end{aligned}
$$

This result indicates that the model also leads to positive assortative matching in the cooperative game setting. 


\section{REFERENCES}

Ahlin, C. 2009. Matching for Credit: Risk and Diversification in Thai Microcredit Groups. BREAD Working Paper No. 251. Durham, NC: Bureau for Research and Economic Analysis of Development.

Ahlin, C., and R. M. Townsend. 2007. "Using Repayment Data to Test Across Models of Joint Liability Lending." Economic Journal 117:F11-F51.

Armendariz de Aghion, B. 1999. "On the Design of a Credit Agreement with Peer Monitoring." Journal of Development Economics 60:79-104.

Armendariz de Aghion, B., and C. Gollier. 2000. "Peer Group Formation in an Adverse Selection Model." Economic Journal 110:632-643.

Armendariz de Aghion, B., and J. Morduch. 2004. “Microfinance: Where Do We Stand?" In Financial Development and Economic Growth: Explaining the Links, edited by C. Goodhart. Basingstoke, UK: Palgrave Macmillan. 2005. The Economics of Microfinance. Cambridge, MA: MIT Press.

Banerjee, A., T. Besley, and T. Guinnane. 1994. "Thy Neighbor's Keeper: The Design of a Credit Cooperative with Theory and a Test." Quarterly Journal of Economics 109:491-515.

Becker, G. 1993. A Treatise on the Family. Cambridge, MA: Harvard University Press.

Chowdury, P. R. 2005. “Group Lending: Sequential Financing, Lending Monitoring, and Joint Liability.” Journal of Development Economics 77:415-439.

Cull, R., A. Demirguc-Kunt, and J. Morduch. 2007. "Financial Performance and Outreach: A Global Analysis of Leading Microbanks." Economic Journal 117:F107-F133.

Fearon, J. D., M. Humphreys, and J. M. Weinstein. 2009. "Can Development Aid Contribute to Social Cohesion after Civil War? Evidence from a Field Experiment in Postconflict Liberia." American Economic Review 99:287-219.

Feigenberg, B., E. Field, and R. Pande. 2011. The Economic Returns to Social Interaction: Experimental Evidence from Microfinance. Working Paper, Harvard University .

Field, E., and R. Pande. 2008. "Repayment Frequency and Default in Microfinance: Evidence from India." Journal of the European Economic Association 6:501-509.

Gan, L., and M. A. Hernandez. 2013. "Making Friends with Your Neighbors? Agglomeration and Tacit Collusion in the Lodging Industry." Review of Economics and Statistics, forthcoming, DOI: 10.1162/REST_a_00289.

Gan, L., and R. Mosquera. 2008. An Empirical Study of the Credit Market with Unobserved Consumer Types. NBER Working Paper 13873. Cambridge, MA: National Bureau of Economic Research.

Gan, L., F. Huang, and A. Mayer. 2011. A Simple Test of Private Information in the Insurance Markets with Heterogeneous Insurance Demand. NBER Working Paper 16738. Cambridge, MA: National Bureau of Economic Research.

Ghatak, M. 1999. Group Lending, Local Information, and Peer Selection. Journal of Development Economics 60:27-50. . 2000. Screening by the Company You Keep: Joint Liability Lending and the Peer Selection Effect. Economic Journal 110:601-631.

Ghatak, M., and T. Guinnane. 1999. The Economics of Lending with Joint Liability: Theory and Practice. Journal of Development Economics 60:195-228.

Gine, X., and D. Karlan. 2009. Group versus Individual Liability: Long Term Evidence from Philippine Microcredit Lending Groups. Working Paper 61, Yale University.

Guttman, J. M. 2008. “Assortative Matching, Adverse Selection, and Group Lending." Journal of Development Economics 87:51-56. 
Hermes, N., and R. Lensink. 2007. “The Empirics of Microfinance: What Do We Know?” Economic Journal 117:110 .

Hermes, N., R. Lensink, and H. Mehrteab. 2005. "Peer Monitoring, Social Ties and Moral Hazard in Group Lending Programmes: Evidence from Eritrea.” World Development 33:149-169.

Karlan, D. 2007. "Social Connections and Group Banking.” Economic Journal 117:52-84.

Li, S., Y. Liu, and K. Deininger. 2012. "How Important Are Endogenous Peer Effects in Group Lending? Estimating a Static Game of Incomplete Information." Journal of Applied Econometrics, forthcoming, DOI: $10.1002 / \mathrm{jae} .2276$.

Maes, J., and L. Reed. 2012. State of the Microcredit Summit Campaign Report 2012. Washington DC: Microcredit Summit Campaign.

McFadden, D., C. Puig, and D. Kirschner. 1977. "Determinants of the Long-Run Demand for Electricity." Proceedings of the American Statistical Association (Business and Economics Section):109-117.

Paxton, J., D. Graham, and C. Thraen. 2000. "Modeling Group Loan Repayment Behavior: New Insights from Burkina Faso." Economic Development and Cultural Change 48:639-655.

Shankar, S. 2006. Transaction Costs in Group Micro Credit in India: Case Studies of Three Microfinance Institutions. Centre for Microfinance, Institute for Financial and Management Research Working Paper. Chennai, India: Centre for Micro Finance.

Sharma, M., and M. Zeller. 1997. "Repayment Performance in Group-based Credit Programs in Bangladesh: An Empirical Analysis.” World Development 25:1731-1742.

Stiglitz, J. 1990. "Peer Monitoring and Credit Markets.” World Bank Economic Review 4:351-366.

van Tassel, E. 1999. “Group Lending under Asymmetric Information.” Journal of Development Economics 60:3-25.

Varian, H. 1990. "Monitoring Agents with Other Agents." Journal of Institutional and Theoretical Economics 146:153-174.

Wydick, B. 1999. "Can Social Cohesion Be Harnessed to Repair Market Failure? Evidence from Group Lending in Guatemala.” Economic Journal 109:463-475.

Zeller, M. 1998. "Determinants of Repayment Performance in Credit Groups: The Role of Program Design, Intragroup Risk Pooling, and Social Cohesion.” Economic Development and Cultural Change 46:599-620. 



\section{RECENT IFPRI DISCUSSION PAPERS}

\section{For earlier discussion papers, please go to www.ifpri.org/pubs/pubs.htm\#dp. All discussion papers can be downloaded free of charge.}

1267. Typology of farm households and irrigation systems: Some evidence from Nigeria. Hiroyuki Takeshima and Hyacinth Edeh, 2013.

1266. Understanding the role of research in the evolution of fertilizer policies in Malawi. Michael Johnson and Regina Birner, 2013.

1265. The policy landscape of agricultural water management in Pakistan. Noora-Lisa Aberman, Benjamin Wielgosz, Fatima Zaidi, Claudia Ringler, Agha Ali Akram, Andrew Bell, and Maikel Issermann, 2013.

1264. Who talks to whom in African agricultural research information networks?: The Malawi case. Klaus Droppelmann, Mariam A. T. J. Mapila, John Mazunda, Paul Thangata, and Jason Yauney, 2013.

1263. Measuring food policy research capacity: Indicators and typologies. Suresh Chandra Babu and Paul Dorosh, 2013.

1262. Does freer trade really lead to productivity growth?: Evidence from Africa. Lauren Bresnahan, Ian Coxhead, Jeremy Foltz, and Tewodaj Mogues, 2013.

1261. Data needs for gender analysis in agriculture. Cheryl Doss, 2013.

1260. Spillover effects of targeted subsidies: An assessment of fertilizer and improved seed use in Nigeria. Lenis Saweda Liverpool-Tasie and Sheu Salau, 2013

1259. The impact of irrigation on nutrition, health, and gender: A review paper with insights for Africa south of the Sahara. Laia Domenech and Claudia Ringler, 2013.

1258. Assessing the effectiveness of multistakeholder platforms: Agricultural and rural management councils in the Democratic Republic of the Congo. Thaddée Badibanga, Catherine Ragasa, and John Ulimwengu, 2013.

1257. The impact of Oportunidades on human capital and income distribution: A top-down/bottom-up approach. Dario Debowicz and Jennifer Golan, 2013.

1256. Filling the learning gap in program implementation using participatory monitoring and evaluation: Lessons from farmer field schools in Zanzibar. Elias Zerfu and Sindu W. Kebede, 2013.

1255. Agricultural mechanization in Ghana: Is specialization in agricultural mechanization a viable business model?: Nazaire Houssou, Xinshen Diao, Frances Cossar, Shashidhara Kolavalli, Kipo Jimah, and Patrick Aboagye, 2013.

1254. A partial equilibrium model of the Malawi maize commodity market. Mariam A. T. J. Mapila, Johann F. Kirsten, Ferdinand Meyer, and Henry Kankwamba, 2013.

1253. Exchange rate policy and devaluation in Malawi. Karl Pauw, Paul Dorosh, and John Mazunda, 2013.

1252. A regional computable general equilibrium model for Honduras: Modeling exogenous shocks and policy alternatives. Samuel Morley and Valeria Piñeiro, 2013.

1251. Agricultural trade: What matters in the Doha Round? David Laborde and Will Martin, 2013.

1250. Opportunities and challenges for community involvement in public service provision in rural Guatemala. Johanna Speer and William F. Vásquez, 2013.

1249. Rising wages in Bangladesh. Xiaobo Zhang, Shahidur Rashid, Kaikaus Ahmad, Valerie Mueller, Hak Lim Lee, Solomon Lemma, Saika Belal, and Akhter Ahmed, 2013.

1248. How are farmers adapting to climate change in Vietnam?: Endogeneity and sample selection in a rice yield model. Bingxin Yu, Tingju Zhu, Clemens Breisinger, and Nguyen Manh Hai, 2013.

1247. Evaluating the local economywide impacts of irrigation projects: Feed the Future in Tanzania. Mateusz Filipski, Dale Manning, J. Edward Taylor, Xinshen Diao, and Angga Pradesha, 2013.

1246. Factor endowments, wage growth, and changing food self-sufficiency: Evidence from country-level panel data . Keijiro Otsuka, Yanyan Liu, and Futoshi Yamauchi, 2013.

1245. Impact of food price changes on household welfare in Ghana. Nicholas Minot and Reno Dewina, 2013. 
INTERNATIONAL FOOD POLICY

RESEARCH INSTITUTE

\section{www.ifpri.org}

\section{IFPRI HEADQUARTERS}

2033 K Street, NW

Washington, DC 20006-1002 USA

Tel.: +1-202-862-5600

Fax: +1-202-467-4439

Email: ifpri@cgiar.org 